\title{
A crosta laterítica ferro-titanífera da Vila Nova Colina e a lateritização no sul de Roraima
}

\author{
Rodrigo Tokuta CASTRO ${ }^{1 *}$, Adriana Maria Coimbra $\mathrm{HORBE}^{1,2}$, Carolina Michelin de ALMEIDA ${ }^{1}$ \\ 1 Universidade Federal do Amazonas, Programa de Pós-graduação em Geociências, Campus Universitário Setor Norte, Bloco 7 - ICE, 69077-000, Manaus, Amazonas, Brasil. \\ 2 Universidade de Brasília, Instituto de Geociências, Campus Universitário Darcy Ribeiro, Brasília, 70910-900, Brasília, Brasil. \\ * Autor correspondente: castrortokuta@gmail.com;
}

\section{RESUMO}

Crostas lateríticas desenvolvidas sobre as rochas do embasamento do Escudo das Guianas (p.e. granitos da Suíte Intrusiva Água Branca) são reconhecidas na região de Vila Nova Colina, localizada ao sul do estado de Roraima. Os objetivos deste trabalho foram estudar as características minerais e geoquímicas dessas crostas lateríticas e avaliar a relação entre elas e as rochas da região, a fim de entender a evolução da lateritização e fornecer informaçóes sobre seu potencial econômico. Este estudo compreende dados de petrografia, mineralogia e litogeoquímica de granitos, quartzo-hornblenda gabro e crostas lateríticas formadas a partir dessas rochas. Os granitos e o quartzo-hornblenda gabro desenvolveram, respectivamente, um tipo específico de crosta laterítica: (i) vermiforme ferruginosa com elevados teores de caulinita, goethita, hematita, magnetita e anatásio e maior concentração de $\mathrm{Al}_{2} \mathrm{O}_{3}, \mathrm{Sc}$, Th, e $\mathrm{Zr}$ e, (ii) maciça ferro-titanífera com altos teores de magnetita, hematita, maghemita, goethita, caulinita, anatásio, gibbsita e ilmenita e de $\mathrm{Fe}_{2} \mathrm{O}_{3}, \mathrm{TiO}_{2}, \mathrm{~V}$ e Cu . Cada tipo de crosta indica o efeito da lateritização na porção sul de Roraima e sua posição topográfica. O posicionamento topográfico mais elevado da crosta maciça $(220 \mathrm{~m})$ e sua composição mineralógica e geoquímica, indicam sua maturidade (isto é, precisou de mais tempo para ser formada) e, portanto relicto de uma fase erosiva na região, provavelmente associada a subsidência da bacia do Tacutu no Mioceno. Enquanto a crosta vermiforme em uma posição mais rebaixada $(140 \mathrm{~m}) \mathrm{sem}$ gibbsita, sugere que ela é mais jovem que a maciça e representa a lateritização imatura do Plio-Pleistoceno.

PALAVRAS CHAVES: Amazônia, ilmenita, anatásio, magnetita, quartzo-hornblenda gabro.

\section{The iron-titaniferous lateritic crust of the Vila Nova Colina and the lateritization in south of Roraima}

\begin{abstract}
Lateritic crusts developed upon the Guiana Shield basement rocks (e.g. granites of the Água Branca Intrusive Suite) was recognized in the Vila Nova Colina region, located in south Roraima state. The objectives of this work were to study the mineral and geochemical characteristics of lateritic crusts and to evaluate the relationship between them and the rocks of the region, in order to understand the evolution of laterization and provide information about the economic potential. This study comprises petrography, mineralogy and litogeochemical investigations of the granites, the quartz-hornblende gabbro and the lateritic crusts formed from these rocks. The granites and the quartz-hornblende gabbro has developed, respectively, a specific type of lateritic crust: (i) the ferruginous vermiform one with high amounts of kaolinite, goethite, hematite, magnetite and anatase, higher concentration of $\mathrm{Al}_{2} \mathrm{O}_{3}, \mathrm{Sc}$, Th e $\mathrm{Zr}$ and, (ii) the iron-titaniferous massive one with high amounts of magnetite, hematite, maghemite, goethite, kaolinite, anatase, gibbsite and ilmenite, and consequently in higher amounts of $\mathrm{Fe}_{2} \mathrm{O}_{3}, \mathrm{TiO}_{2}$, $\mathrm{V} \mathrm{e} \mathrm{Cu}$. Each crust type indicates the effect of the lateritization in the south portion of Roraima and their topographic position. The higher topographic position of the massive crust $(220 \mathrm{~m})$, its mineral and geochemical composition, indicate the maturity (i.e. needed more time to be formed) and may represent a relict of an erosion phase in the region, probably associated with a subsidence of the Tacutu basin in the Miocene. Otherwise, the vermiform crust formed at a lower topographic position $(140 \mathrm{~m})$ with no gibbsite, suggests that it is younger than the massive one and represents the immature laterization of the Plio-Pleistocene.
\end{abstract}

KEYWORDS: Amazônia, ilmenite, anatase, magnetite, quartz-hornblende gabbro. 


\section{INTRODUÇÃO}

Os lateritos são resultantes do processo de intemperismo que ocorre desde que as primeiras rochas são expostas a ação do clima quente e úmido da regiấo intertropical da Terra localizada entre $30^{\circ} \mathrm{N}$ e $30^{\circ} \mathrm{S}$. Nesta zona onde se insere a Amazônia, estão cerca de $40 \%$ das terras emersas das quais $33 \%$ são cobertas por formaçóes lateríticas (Tardy 1993). Devido ao ciclo das rochas estão preservados quase que exclusivamente os lateritos produzidos no Cenozóico e a Amazônia, por estar na região intertropical nos últimos 100 Ma (Tardy e Roquin 1998), têm excelentes exposiçōes dessas formaçōes (Costa 1997; Kotschoubey et al. 2005; Costa et al. 2014 e suas referências).

As rochas geradoras dos perfis lateríticos são diversas, de diferentes idades e composiçôes petrogenéticas, o que favoreceu a geração de diferentes tipos de crostas lateríticas como indicam os trabalhos citados anteriormente. Elas podem ser exclusivamente ferruginosas, que são as mais abundantes, ou o Fe pode estar associado com Ti, Mn, Al e P de acordo com a composiçâo da rocha máe e a idade da crosta (Costa 2007). Além da Amazônia brasileira, as crostas se estendem para a Venezuela, Guianas (Tiesen et al. 1996; Théveniaut e Freyssinet 1999; Soler e Lasaga 2000) e para o nordeste e sudeste do Brasil (Carvalho et al. 1991; Silva e Oliveira 1992; Oliveira et al. 2013 entre outros).
Crostas lateríticas ferro-titaníferas em geral se desenvolvem a partir de complexos ultramáficos-alcalinos-carbonatíticos e são descritas na Amazônia nas Serra de Maraconaí, no Município de Almerim e na Serra de Maicuru no Município de Monte Alegre, ambas no estado do Pará (Oliveira et al. 1988; Angélica e Costa 1991 e 1993; Costa et al. 1991). Crostas manganesíferas podem se formar a partir de rochas sedimentares com concentraçóes elevadas de Mn (Costa et al. 2005 e Silva et al. 2012), crostas aluminosas ou bauxíticas a partir de rochas sedimentares e ígneas félsicas (Boulangé e Carvalho 1997; Kotschoubey et al. 2005; Peixoto e Horbe 2008) e fosfáticas a partir de rochas carbonatíticas e metassedimentares (Costa 1991; Toledo et al. 2006).

$\mathrm{Na}$ Vila de Nova Colina, ao sul do município de Rorainópolis, Roraima (0³5’ N - 050’ N e 60²0' W - 60³5' W), com acesso pela BR 174 e vicinais próximas (Figura 1A), há uma pequena colina com cerca de $220 \mathrm{~m}$ de altitude e um quilômetro de diâmetro onde ocorre um quartzo-hornblenda gabro identificado pela primeira vez na regiâo, sobre a qual se desenvolveu uma crosta ferro-titanífera. Sobre os granitos da Suíte Intrusiva Água Branca, no entorno da colina ocorre crosta vermiforme ferruginosa. Os objetivos deste trabalho foram estudar as características minerais e geoquímicas dessas crostas lateríticas e avaliar a relação entre elas e as rochas da regiáo, a fim de entender a evolução da lateritização e fornecer informaçôes sobre seu potencial econômico.

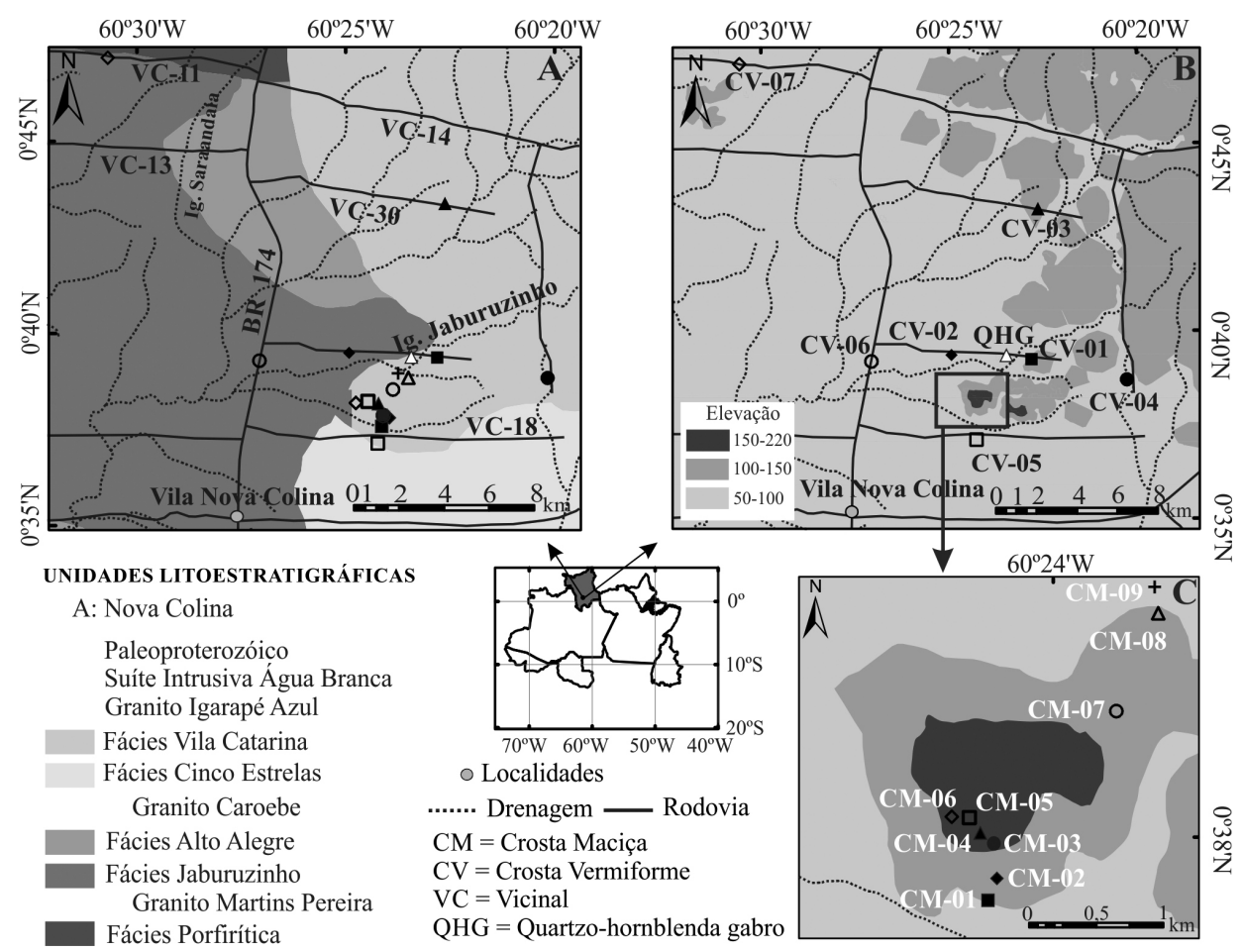

Figura 1. Mapas geológico e de localização modificado de Almeida (2006) (A), mapa geomorfológico (B) e de detalhe (C) da região de Nova Colina. 


\section{MATERIAL E MÉTODOS}

Para o desenvolvimento do presente estudo foram coletadas 17 amostras (Figura 1), das quais uma do quartzohornblenda gabro (QHG), nove de crosta ferro-titanífera (CM-01, CM-02, CM-03, CM-04, CM-05, CM-06, CM07, CM-08 e CM-09) e sete de crosta vermiforme (CV-01, CV-02, CV-03, CV-04, CV-05, CV-06, CV-07). Além dessas amostras foram utilizados dados geoquímicos de 26 amostras de rochas, sendo 14 do Granito Caroebe (Fácies Jaburuzinho) e 12 do Igarapé Azul (Fácies Vila Catarina) de Almeida (2006).

As amostras foram descritas macro e microscopicamente com auxílio de lupa, microscópio petrográfico, difração de raios-X (DRX - Shimadzu XRD - 6000, Kyoto, Japão), microscopia eletrônica de varredura (MEV: FEI-QUANTA 250, Hillsboro, OR, USA) nos Laboratórios de Microscopia e Técnicas Mineralógicas da Universidade Federal do Amazonas e microssonda eletrônica (JEOL JXA 8230, Tóquio, Japão) no Laboratório de Microssonda Eletrônica da Universidade de Brasília.

Foram analisados óxidos maiores, menores, e elementos traços $\left(\mathrm{SiO}_{2}, \mathrm{Al}_{2} \mathrm{O}_{3}, \mathrm{Fe}_{2} \mathrm{O}_{3}, \mathrm{MgO}, \mathrm{CaO}, \mathrm{Na}_{2} \mathrm{O}, \mathrm{K}_{2} \mathrm{O}, \mathrm{TiO}_{2}\right.$, $\mathrm{P}_{2} \mathrm{O}_{5}$, PF, Ag, Au, As, Ba, Be, Bi, Co, Cr, Cs, Cu, Ga, Hf, Mn, Mo, Nb, Ni, Pb, Rb, Sb, Sc, Sn, Sr, Ta, Th, U, V, W, Y, Yb $\mathrm{Zn}, \mathrm{Zr}$ e ETR) por fusão alcalina (metaborato e tetraborato de lítio) e dissolução ácida e determinados por ICP-ES e ICPMS (Famílias 4A e 4B). A perda ao fogo foi determinada por gravimetria. As análises químicas das amostras foram realizadas na Acmelabs Ltd., Vancouver, Canadá.

$\mathrm{O}$ fracionamento dos ETR $(\mathrm{La} / \mathrm{Yb})_{\mathrm{N}}$, assim como as razóes $\mathrm{Ce} / \mathrm{Ce}^{*}$ e Eu/Eu* foram calculadas em relação a crosta continental de Taylor e McLennan (1985), sendo as duas últimas obtidas através das equaçóes 1 e 2 .

(1) $\mathrm{Ce} / \mathrm{Ce}^{*}=\left[\left(\mathrm{Ce}_{\mathrm{N}}\right) /\left(\sqrt{ }\left(\mathrm{La}_{\mathrm{N}}\right)^{*}\left(\operatorname{Pr}_{\mathrm{N}}\right]\right.\right.$

(2) $\mathrm{Eu} / \mathrm{Eu}^{*}=\left[\left(\mathrm{Eu}_{\mathrm{N}}\right) /\left(\sqrt{ }\left(\mathrm{Sm}_{\mathrm{N}}\right)^{*}\left(\mathrm{Gd}_{\mathrm{N}}\right]\right.\right.$

A identificação das associaçôes geoquímicas e a determinaçáo da similaridade entre as amostras foram feitas por métodos estatísticos utilizando o programa Statistica (versão 7.0). Inicialmente utilizou-se o método de análise de fatores que permitiu identificar $\mathrm{SiO}_{2}, \mathrm{Al}_{2} \mathrm{O}_{3}, \mathrm{Fe}_{2} \mathrm{O}_{3}, \mathrm{TiO}_{2}$, $\mathrm{P}_{2} \mathrm{O}_{5}, \mathrm{PF}, \mathrm{Ba}, \mathrm{Co}, \mathrm{Hf}, \mathrm{Nb}, \mathrm{Rb}, \mathrm{Sr}, \mathrm{V}, \mathrm{Y}, \mathrm{Zr}$ e ETR exceto Ce como os elementos com maior carga (superior a 0,3 ). Posteriormente, esses elementos foram utilizados na análise de agrupamento em modo simples e espaçamento 1-Person-r, o que permitiu determinar a similaridade geoquímica entre as amostras e as associaçóes geoquímicas entre os óxidos e os demais elementos.

No cálculo isoquímico foram utilizados todos os elementos químicos que compóem as rochas e as crostas exceto $\mathrm{Al}_{2} \mathrm{O}_{3}$, por ser considerado imóvel durante o intemperismo, além de $\mathrm{CaO}, \mathrm{MgO}, \mathrm{Na}_{2} \mathrm{O}, \mathrm{K}_{2} \mathrm{O}, \mathrm{Ag}$, As, $\mathrm{Au}, \mathrm{Be}, \mathrm{Bi}, \mathrm{Cd}, \mathrm{Cr}, \mathrm{Cs}, \mathrm{Hg}$,
Mn, Sb, Se, Sn, Ta e Tl. Por estarem, na sua grande maioria, abaixo do limite de detecção. $\mathrm{O} \mathrm{TiO}_{2}$ foi utilizado como imóvel e o cálculo utilizou a seguinte fórmula:

(3) $\mathrm{FE}=\left[\mathrm{Ce}(\mathrm{hz})^{*} \mathrm{TiO}_{2}(\mathrm{rm})\right] /\left[\mathrm{Ce}(\mathrm{rm})^{*} \mathrm{TiO}_{2}(\mathrm{hz})\right]$, onde:

$\mathrm{FE}=$ fator de enriquecimento, $\mathrm{Ce}(\mathrm{hz})=$ concentração do elemento no horizonte, $\mathrm{Ce}(\mathrm{rm})$ = concentração do elemento na rocha mãe, $\mathrm{TiO}_{2}(\mathrm{hz})=$ concentração do $\mathrm{TiO}_{2}$ no horizonte e $\mathrm{Ci}(\mathrm{rm})=$ concentração do $\mathrm{TiO}_{2}$ na rocha mãe. Como base nessa fórmula os elementos com valores de $\mathrm{FE}>1,1$ são considerados enriquecidos, FE entre 0,9 e 1,1 considerados imóveis e $\mathrm{FE}<0,9$ considerados empobrecidos em relação a rocha mãe.

$\mathrm{Na}$ confecção dos mapas foram utilizados os softwares Global Mapper 12 e ArcMap 10.0.

\section{Contexto Geológico e Geomorfológico Regional}

A regiáo de Nova Colina (Província Ventuari-Tapajós com 1,9 - 1,8 Ga de Tassinari e Macambira 1999 ou Domínio Uatumã-Anauá 2,03 Ga de Santos et al. 2000) reúne os Granitos Martins Pereira, Caroebe e Igarapé Azul da Suíte Intrusiva Água Branca do Cráton das Guianas, metamorfizados em fácies xisto verde e anfibolito e com idades entre 2,03 e 1,89 Ga (Almeida et al. 2007). O Granito Martins Pereira é composto por granodioritos a monzogranitos cinza porfiríticos, (Almeida e Macambira 2007). O Granito Caroebe é dividido em fácies Jaburuzinho $(1,90 \mathrm{Ga})$ formada por granodioritos, monzogranitos e tonalitos, com hornblenda como mineral diagnóstico das rochas dessa fácies, enquanto a fácies Alto Alegre $(1,89 \mathrm{Ga})$ composta dominantemente por biotita-monzogranitos com enclaves remanescentes da fácies Jaburuzinho (Almeida e Macambira 2007). O Granito Igarapé Azul $(1,89 \mathrm{Ga})$, compreende três fácies : Vila Catarina abrange monzogranitos e raros sienogranitos cinzas e rosados, com textura fanerítica média a grossa, Saramandaia inclui monzogranitos, granodioritos e leucogranitos rosados porfiríticos, e Cinco Estrelas envolve monzogranitos, sienogranitos, granodioritos e quartzo-monzonitos acinzentados, equigranulares, com textura fanerítica fina a média (Almeida e Macambira 2007). O QHG (0’39' $16^{\prime \prime} \mathrm{N}$ e 60 23' 26”), mapeado pela primeira vez na etapa de campo que deu origem a este trabalho, é provavelmente membro da fácies Jaburuzinho do granito Caroebe.

O relevo da região da Vila Nova Colina é dominado pelo Pediplano Rio Branco-Rio Negro (Franco et al. 1975) que é a superfície rebaixada onde afloram crostas lateríticas vermiformes. É truncado pelos Planaltos Residuais de Roraima onde se insere a colina e ocorre a crosta ferro-titanífera (Figura 1B). O relevo formado por essas duas superfícies é suave com altitudes entre 87 $\mathrm{m}$ nas drenagens a $140 \mathrm{~m}$ nas colinas. Inselbergs com até 1000 $\mathrm{m}$ de altitude são destaque na topografia da região. A cobertura vegetal é de floresta tropical e o clima é quente e úmido. 


\section{RESULTADOS}

O QHG classificado pelos diagramas de Streckeisen (1976) e TAS (Cox et al. 1979), a partir do qual se desenvolveu a crosta ferro-titanífera, é constituído por 50\% de hornblenda (cristais 0,2 a $4,5 \mathrm{~mm}$ de comprimento), $22 \%$ de labradorita, $15 \%$ de quartzo, $5 \%$ de clorita como produto de alteração da hornblenda (Figura 2A e 2B), 4\% de ilmenita, $2 \%$ de magnetita, além de titanita, allanita, pirita, calcopirita, espinélio e calcita como acessórios (2\%). Com auxílio da microssonda eletrônica foram identificados no QHG e na crosta maciça geikelita $\left(\mathrm{MgTiO}_{3}\right)$ e pirofanita $\left(\mathrm{MnTiO}_{3}\right)$ que são, respectivamente os membros magnesianos e manganesíferos da ilmenita, (Figura 2C). Nas partiçôes da magnetita ocorrem lamelas de exsoluçâo acinzentadas de hematita (lamelas cruzadas - Klein e Dutrow 2007) e ilmenita (lamelas paralelas). Também foi identificada titanomagnetita em cristais bem formados, normalmente em contato retos entre si e com magnetita e ilmenita.

As rochas do Granito Igarapé Azul (Fácies Vila Catarina) e do Granito Caroebe (Fá cies Jaburuzinho), a partir das quais se desenvolveu a crosta vermiforme, são constituídas de plagioclásio, quartzo, feldspato potássico, biotita, hornblenda, magnetita, titanita, epidoto, apatita, zircão e allanita (mais detalhes estão em Almeida e Macambira 2007).

A crosta maciça ferro-titanífera formada a partir do QHG, é marrom avermelhada a cinza escura, geralmente com brilho metálico, pouco porosa a microporosa e magnética (Figura 3A e 3B). É composta por magnetita, hematita, maghemita, goethita, caulinita, anatásio, gibbsita e ilmenita (Figuras 2, 3 e 4). Os cristais bem formados e com até $5 \mathrm{~mm}$ de diâmetro de magnetita e titanomagnetita herdados da rocha mãe, representam até $95 \%$ da composição da crosta (Figuras $2 \mathrm{D}$ e 2E). Há ainda cristais límpidos de ilmenita, também herdados, que estão seccionados por anatásio identificado por DRX (Figura 2E) resultante da alteraçáo da ilmenita por oxidaçấo do $\mathrm{Fe}^{2+}$ (Schroeder et al. 2005), além de geikelita e pirofanita. A maghemita é cinza escura na seção polida e tem contato irregular com os cristais de magnetita e ilmenita (Figura $2 \mathrm{C}$ e $2 \mathrm{~F}$ ) e é resultante do intemperismo da magnetita. As espécies minerais são as mesmas que as da crosta de Maicuru e Maraconaí, mas a quantidade de anatásio é inferior (10\%) aos 50\% de Maicuru (Angélica e Costa 1993). Além desses minerais, a crosta maciça possui manchas brancas milimétricas de caulinita (Figura 3A) provenientes do intemperismo da labradorita e poros preenchidos por caulinita, gibbsita, goethita e quartzo (Figura 4A, 4B e 4C).

A presença da paragênese magnetita + maghemita + ilmenita + hematita + goethita + caulinita + gibbsita + anatásio na crosta maciça, além dos contatos irregulares entre maghemita e os cristais de magnetita e ilmenita, em relaçấo ao contato reto observado no QHG e a ocorrência de gibbsita
(CM-05, Figura 4C), indicam que realmente se trata de uma crosta laterítica formada a partir do QHG. O processo de lateritização dessa crosta promoveu a oxidação do $\mathrm{Fe}^{2+}$ da ilmenita $\left.(\mathrm{FeTiO})_{3}\right)$ e magnetita $\left(\mathrm{FeO} \cdot \mathrm{Fe}_{2} \mathrm{O}_{3}\right)$, a transformação da magnetita em maghemita segundo as reaçóes de Schroeder et al. (2005) abaixo:

$3 \mathrm{Fe}^{2+}{ }_{0,93} \mathrm{TiO}_{3} \rightarrow \mathrm{Fe}^{3+}{ }_{1,86} \mathrm{Ti}_{3} \mathrm{O}_{9}+{ }_{0,93} \mathrm{Fe}^{3+}+\mathrm{e}^{-}$ilmenita $\rightarrow$ pseudorutilo (1)

FeO. $\mathrm{Fe}_{2} \mathrm{O}_{3} \rightarrow \gamma \mathrm{Fe}_{2} \mathrm{O}_{3}$ magnetita $\rightarrow$ maghemita (2)

$\mathrm{Fe}^{3+}{ }_{1,86} \mathrm{Ti}_{3} \mathrm{O}_{9} \rightarrow 3 \mathrm{TiO}_{2}+0,93 \mathrm{Fe}_{2} \mathrm{O}_{3}$ pseudorutilo $\rightarrow$ anatásio + hematita (3)

$\mathrm{Fe}_{2} \mathrm{O}_{3}+\mathrm{H}_{2} \mathrm{O} \rightarrow 2 \mathrm{FeOOHhematita}+$ água $\rightarrow$ goethita (4)

As equaçóes demonstram que nesse processo a ilmenita se transformou em pseudorutilo (fase intermediária), que gerou anatásio e hematita e esta por hidrataçấo formou goethita. A caulinizaçáo por hidrólise da labradorita e a posterior dessilicificação evoluiu para gibbsita, promoveu a lixiviaçấo dos álcalis e o acúmulo de Fe e Al (Beauvais e Roquin 1996, Anand e Paine 2002). A presença de $95 \%$ de magnetita e titanomagnetita em relação aos 8\% de magnetita+ilmenita no QHG indica que a lateritização provocou enriquecimento residual desses minerais, mas foi insuficiente para aumentar consideravelmente o teor de anatásio (máximo de 10\%) como ocorreu em Maicuru e Maraconaí, onde esse mineral alcança 50\% na crosta em Maicuru (Angélica e Costa 1993). Esse fato poderia também justificar a ausência de crosta bauxítica, comum em perfis lateríticos mais evoluídos como os de Maicuru e Maraconaí (Oliveira et al. 1988 Angélica e Costa 1991 e 1993; Costa et al. 1991), apesar da erosão ser um fator a ser considerado.

As crostas ferruginosas vermiformes desenvolvidas a partir dos granitos Caroebe e Igarapé Azul e que ocorrem nas porçôes rebaixadas do entorno da colina onde aflora a crosta maciça, são friáveis, têm arcabouço poroso amarelado a avermelhado devido a maior abundância de caulinita que a goethita . Sáo constituídas também por hematita, quartzo e anatásio, com raros nódulos e pisólitos avermelhados a violeta de até $20 \mathrm{~mm}$ de diâmetro geralmente com filmes de goethita (Figura 3). A textura e a composição mineral dessas crostas se assemelham as crostas encontradas na regiáo na serra da Prata e no entorno da Serra do Tucano, ambas a norte de Nova Colina (Conceição 2011 e Santos 2011).

\section{Composição Química}

No QHG predomina $\mathrm{SiO}_{2}(46,8 \%)$, seguido de $\mathrm{Fe}_{2} \mathrm{O}_{3} \mathrm{e}$ $\mathrm{Al}_{2} \mathrm{O}_{3}(15,5$ e 13,9\%, respectivamente) e entre os álcalis $\mathrm{CaO}$ e $\mathrm{MgO}$ são os mais elevados (9,9 e 5,8 \%, respectivamente). Nos granitos predominam $\mathrm{SiO}_{2}$ (até 69,75\%) e $\mathrm{Al}_{2} \mathrm{O}_{3}$ (até 

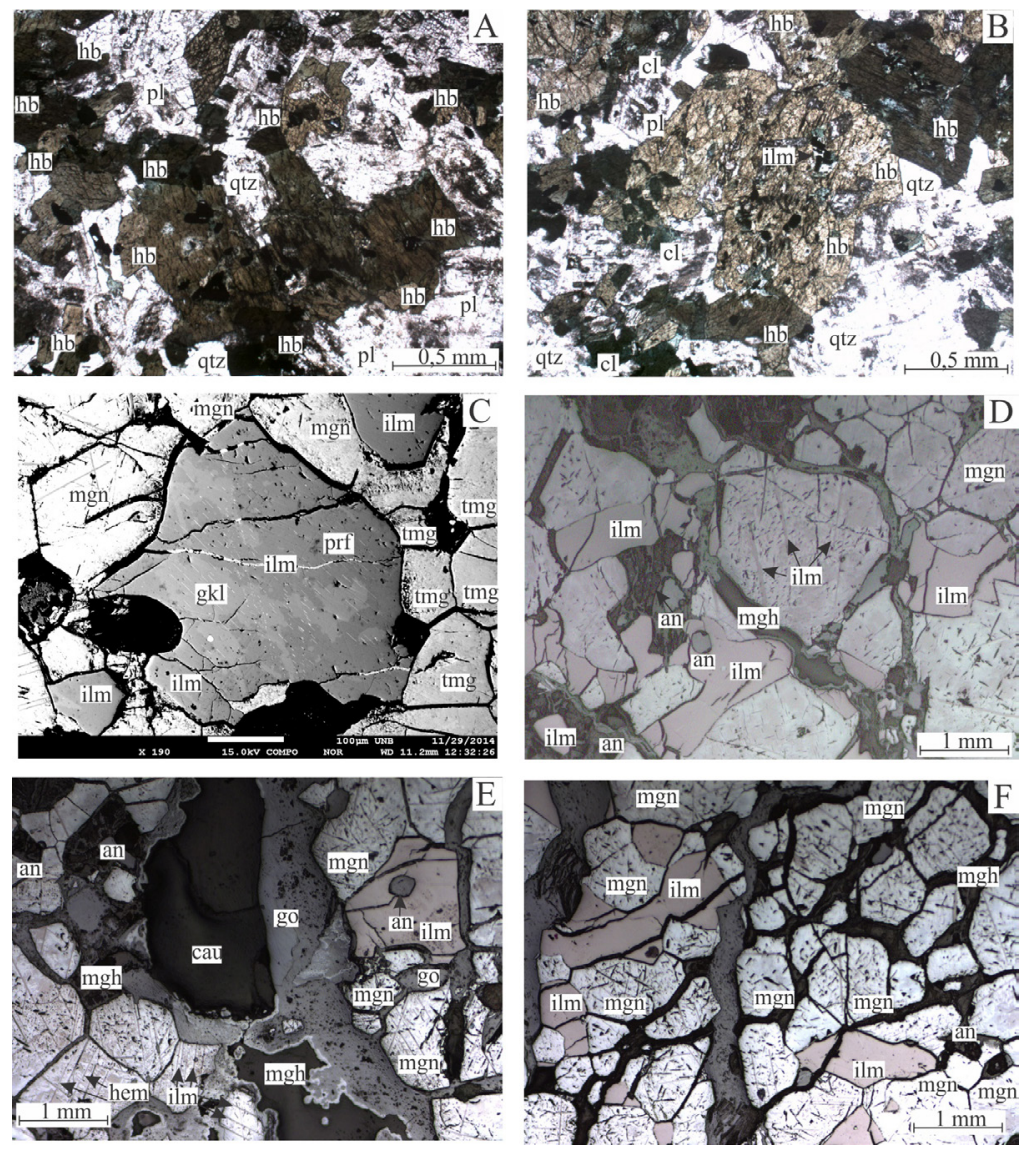

Figura 2. Aspectos microscópicos do QHG e da crosta maciça ferro-titanífera de Nova Colina. A. Aspecto geral do QHG, exibindo as acumulações de hornblenda, grande quantidade de minerais opacos (ilmenita + magnetita +titanomagnetita) e plagioclásios. B. Cristais de hornblenda com alterações para clorita, inclusões de minerais opacos, plagioclásio com indícios de dessilicificação. C. Ilmenita em solução sólida com pirofanita (cinza mais escuro) e geikilita (cinza mais claro), titanomagnetitas bem cristalizadas em contato com ilmenita e magnetita. D. Magnetita com lamelas de ilmenita (lamelas paralelas) nas clivagens e ilmenita bem formadas, ambas envolvidas por maghemita e matriz argilosa (goethita e caulinita). E. Porções escuras que ocorrem entre os cristais de magnetita e ilmenita e correspondem as machas brancas encontradas na crosta maciça e cristal de ilmenita (rosado) fraturado com indícios de alteração para anatásio. F. Crosta maciça ferro-titanífera com cristais de magnetita envolvidos por exsolução de maghemita, cristais límpidos de ilmenita e matriz argilosa cinza e preta constituída de goethita e caulinita. Ant = anatásio, $\mathrm{Chl}=$ clorita, $\mathrm{Gkl}=$ geikilita, $\mathrm{Gt}=$ goethita, $\mathrm{Hbl}=$ hornblenda, $\mathrm{Hem}=$ hematita, $\mathrm{Ilm}=\mathrm{ilmenita}, \mathrm{Kln}=\mathrm{caulinita}, \mathrm{Mag}$ = magnetita, $\mathrm{Mgh}=$ maghemita, $\mathrm{PI}$ = plagioclásio, $\mathrm{Prf}=$ pirofanita, $\mathrm{Qtz}=$ quartzo e Tmag = titanomagnetita. "esta figura é colorida na versão eletrônica"
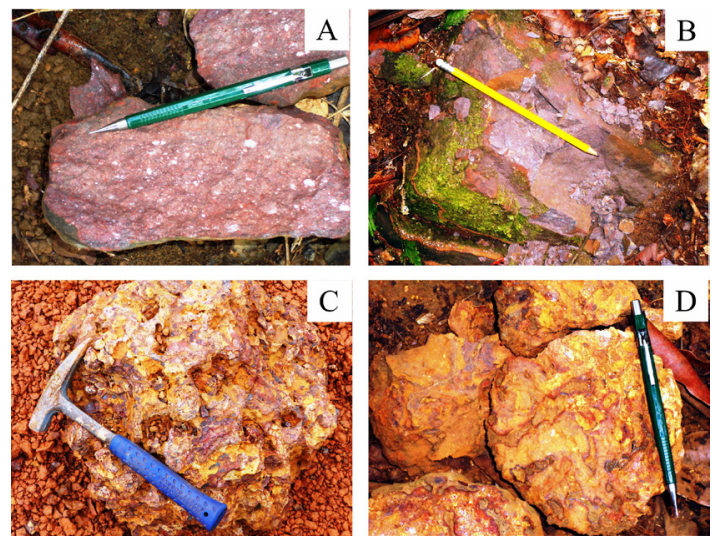

Figura 3. Aspectos macroscópicos das crostas lateríticas de Nova Colina. A. Crosta maciça ferro-titanífera avermelhada com manchas esbranquiçadas de caulinita. B. Crosta maciça ferro-titanífera acinzentada com brilho metálico formada por magnetita, maghemita, ilmenita, hematita, goethita, caulinita, gibbsita e anatásio C. Crosta vermiforme ferruginosa com arcabouço endurecido formado por hematita e goethita, preenchido por caulinita e quartzo. D. Crosta vermiforme ferruginosa formada por arcabouço avermelhado de hematita e goethita preenchido por caulinita amarelada e quartzo. "esta figura é colorida na versão eletrônica" 

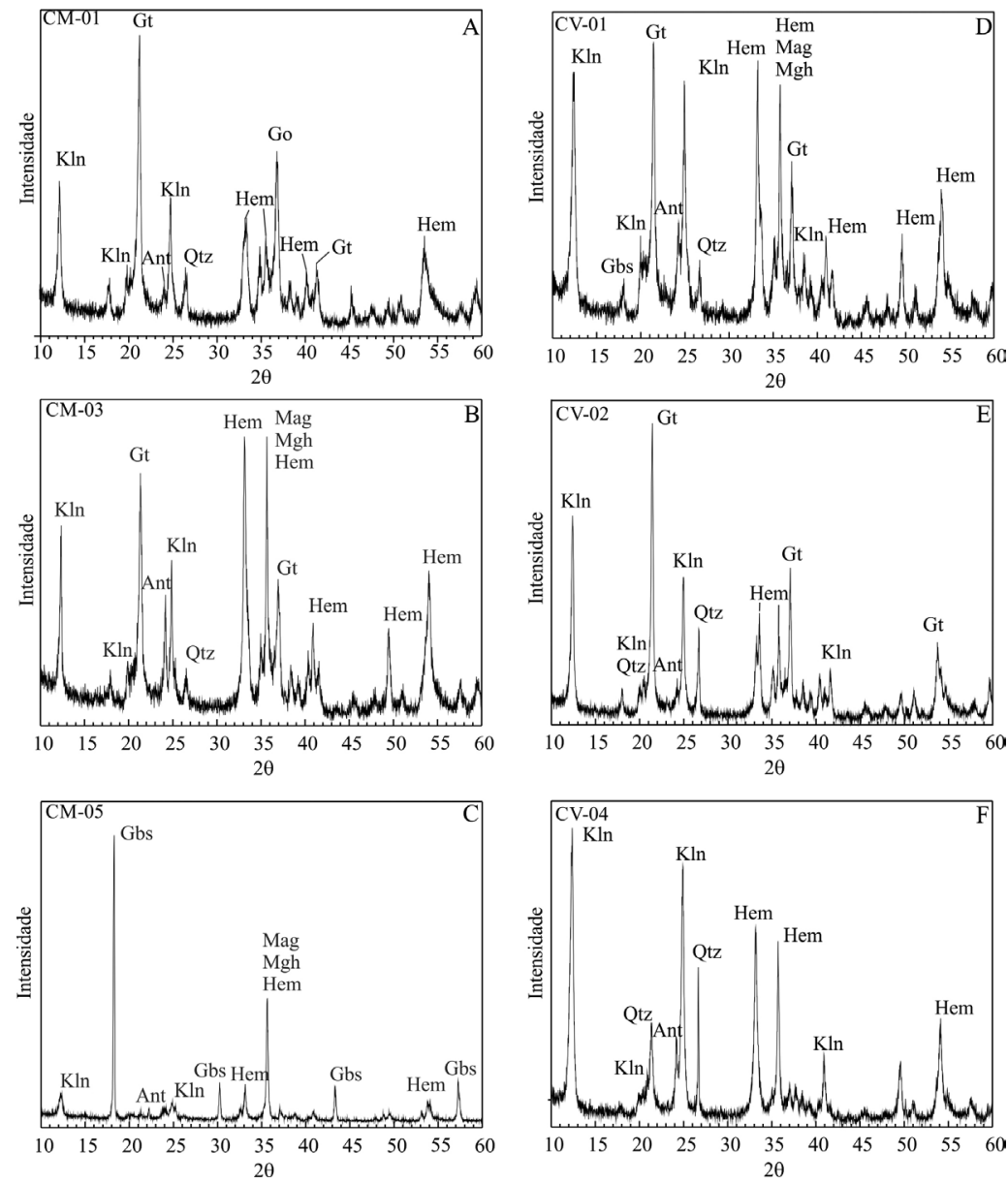

Figura 4. Difratogramas da crosta maciça (A, B e C) e vermiforme ferruginosa (D, E e F). Ant=anatásio, Gbs=gibbsita, Gt=goethita, Hem=hematita, $\mathrm{Kln}=$ Caulinita, $\mathrm{Mag}=$ magnetita e $\mathrm{Mgh}=$ magnetita .

$18,24 \%)$, seguidos dos álcalis $\mathrm{CaO}(5,54 \%$, granito Caroebe) e $\mathrm{K}_{2} \mathrm{O}(5,33 \%$, granito Igarapé Azul).

Ferro $(46,3$ a $76,9 \%)$ e $\mathrm{TiO}_{2}$ (até $\left.10,1 \%\right)$ são mais elevados nas crostas maciças e $\mathrm{SiO}_{2}$ e $\mathrm{Al}_{2} \mathrm{O}_{3}$ (até 29, 9 e 21,9\%, respectivamente) na crosta vermiforme. A PF (até 10,5\% nas maciças e $14,1 \%$ nas vermiforme) nas crostas é mais elevada que nas rochas (Tabela 1).

A distribuiçấo dos elementos traços mostra que os mais concentrados no QHG são Sr, V, Ba e Zr (530, 338, 263 e $215 \mathrm{ppm}$, respectivamente), nos granitos $\mathrm{Ba}, \mathrm{Sr}$ e $\mathrm{Zr}$ (média de 1622,751 e 346 respectivamente) e em ambas as crostas são $\mathrm{V}, \mathrm{Zr}$ e Cu (média de 968, 175 e 112 ppm respectivamente), (Tabela 2). No QHG Co, Cu, Ga, Nb, Sc, Sr, V e Zr estão enriquecidos em relação a crosta continental superior de Taylor e McLennan (1985), enquanto $\mathrm{Ba}, \mathrm{Hf}, \mathrm{Pb}, \mathrm{Rb}, \mathrm{Th}, \mathrm{U}$, $\mathrm{Y}$ e $\mathrm{Zn}$ estão empobrecidos (Figura $5 \mathrm{~A}$ ). O enriquecimento se acentua em $\mathrm{Co}, \mathrm{Cu}, \mathrm{Ga}$, Sc e V nas crostas maciças, assim como o empobrecimento em Ba, Hf, Rb, Sr, Th, U, Y e Zn.
Os granitos, quimicamente similares entre si, são enriquecidos em relação a crosta continental superior de Taylor e McLennan (1985) em Ba, Ga, Hf, Sr, Th e Zr e empobrecidos em $\mathrm{Co}, \mathrm{Cu}, \mathrm{Nb}, \mathrm{Pb}, \mathrm{Sc}, \mathrm{V}, \mathrm{Y}$ e Zn, enquanto a crosta laterítica vermiforme, desenvolvida a partir dessas rochas, é enriquecida apenas em $\mathrm{Ga}, \mathrm{Pb}$, Th, $\mathrm{U}$ e V e empobrecida em Ba, Hf, Rb, Sr e Zr (Figura 5B). A diferença entre as crostas é o maior enriquecimento em $\mathrm{V}, \mathrm{Cu}, \mathrm{Ga}$ e Co na maciça em relaçáo ao enriquecimento em $\mathrm{Sc}, \mathrm{Th}, \mathrm{Pb}, \mathrm{U}$ e $\mathrm{Zr}$ na vermiforme e retrata o efeito da lateritizaçáo sobre o QHG e os granitos, respectivamente. Outra característica resultante da lateritizaçáo é empobrecimento em $\mathrm{Ba}, \mathrm{Hf}, \mathrm{Nb}$ e $\mathrm{Rb}$ na crosta maciça e em Y e Zn na crosta vermiforme.

Nas crostas maciças os ETRL (média de 210,6 ppm) estão empobrecidos em relaçáo ao QHG, assim como a crosta vermiforme (média de 71,2 ppm) em relação aos granitos (média de $332 \mathrm{ppm}$ ) (Tabela 3). A crosta maciça tem maior concentração em Ce (média de 94,1 ppm) e as vermiformes em La (média de 20,9ppm). Outra diferença é 
Tabela 1. Composição química dos óxidos maiores, menores e perda ao fogo em \% das rochas, crostas maciças e vermiformes. QHG = quartzo-hornblenda gabro, GIA = Granito Igarapé Azul (Fácies Vila Catarina) e GC = Granito Caroebe (Fácies Jaburuzinho).

\begin{tabular}{|c|c|c|c|c|c|c|c|c|c|c|}
\hline & $\mathrm{SiO}_{2}$ & $\mathrm{Al}_{2} \mathrm{O}_{3}$ & $\mathrm{Fe}_{2} \mathrm{O}_{3}$ & $\mathrm{~K}_{2} \mathrm{O}$ & $\mathrm{Na}_{2} \mathrm{O}$ & $\mathrm{CaO}$ & $\mathrm{MgO}$ & $\mathrm{TiO}_{2}$ & $\mathrm{P}_{2} \mathrm{O}_{5}$ & PF \\
\hline CM-01 & 17,99 & 18,91 & 46,29 & 0,05 & $<0,01$ & $<0,01$ & 0,02 & 1,74 & 0,46 & 13,60 \\
\hline CM-02 & 12,22 & 9,90 & 66,95 & 0,08 & $<0,01$ & 0,01 & $<0,01$ & 3,60 & 0,16 & 6,60 \\
\hline CM-03 & 13,71 & 14,54 & 56,15 & 0,01 & $<0,01$ & $<0,01$ & 0,03 & 3,51 & 0,23 & 10,50 \\
\hline CM-04 & 3,51 & 4,11 & 76,91 & $<0,01$ & $<0,01$ & $<0,01$ & 0,03 & 5,09 & 0,23 & 8,30 \\
\hline CM-05 & 5,93 & 10,54 & 65,50 & $<0,01$ & $<0,01$ & $<0,01$ & 0,47 & 10,08 & 0,06 & 5,40 \\
\hline CM-06 & 11,38 & 9,94 & 66,98 & 0,09 & $<0,01$ & $<0,01$ & $<0,01$ & 2,54 & 0,20 & 8,30 \\
\hline CM-07 & 13,11 & 10,95 & 62,55 & 0,19 & $<0,01$ & $<0,01$ & $<0,01$ & 3,53 & 0,09 & 8,80 \\
\hline CM-08 & 9,19 & 7,67 & 71,21 & 0,04 & $<0,01$ & $<0,01$ & $<0,01$ & 3,57 & 0,41 & 6,50 \\
\hline CM-09 & 9,70 & 8,21 & 66,79 & 0,06 & $<0,01$ & $<0,01$ & $<0,01$ & 3,55 & 0,17 & 10,20 \\
\hline $\mathrm{QHG}$ & 46,80 & 13,93 & 15,50 & 0,54 & 2,61 & 9,96 & 5,80 & 2,24 & 0,76 & 1,40 \\
\hline CV-01 & 20,29 & 19,71 & 46,00 & 0,38 & $<0,01$ & $<0,01$ & $<0,01$ & 0,85 & 0,16 & 12,20 \\
\hline CV-02 & 25,17 & 17,26 & 44,04 & 0,12 & $<0,01$ & $<0,01$ & $<0,01$ & 0,50 & 0,05 & 12,00 \\
\hline CV-03 & 33,19 & 15,54 & 40,52 & 0,22 & $<0,01$ & $<0,01$ & $<0,01$ & 0,36 & 0,10 & 9,80 \\
\hline CV-04 & 28,84 & 15,94 & 44,72 & 0,17 & $<0,01$ & $<0,01$ & $<0,01$ & 0,63 & 0,07 & 9,40 \\
\hline CV-05 & 21,53 & 19,10 & 47,01 & 0,08 & $<0,01$ & $<0,01$ & $<0,01$ & 0,58 & 0,06 & 11,30 \\
\hline CV-06 & 24,09 & 21,89 & 38,70 & 0,20 & $<0,01$ & $<0,01$ & $<0,01$ & 0,75 & 0,09 & 14,10 \\
\hline CV-07 & 29,91 & 14,41 & 46,03 & 0,29 & $<0,01$ & $<0,01$ & 0,02 & 0,66 & 0,08 & 8,30 \\
\hline GIA & 69,75 & 15,59 & 1,82 & 5,33 & 3,83 & 2,02 & 0,40 & 0,28 & 0,11 & 0,65 \\
\hline $\mathrm{GC}$ & 59,40 & 18,24 & 4,96 & 2,99 & 4,33 & 5,54 & 1,82 & 0,72 & 0,53 & 0,97 \\
\hline Média crosta maciça & 10,75 & 10,53 & 64,37 & 0,07 & $<0,01$ & 0,01 & 0,14 & 4,13 & 0,22 & 8,69 \\
\hline Média crosta vermiforme & 26,15 & 17,69 & 43,86 & 0,21 & $<0,01$ & $<0,01$ & 0,02 & 0,62 & 0,09 & 11,01 \\
\hline
\end{tabular}

Tabela 2. Distribuição dos elementos traços em ppm das rochas, crostas maciças e vermiformes. Elementos menores que 0 limite de detecção: Au $(<0,5$ ppb), Hg (<0,01 ppm), Be, Cd, Sb, Sn, Ta e Tl (<0,1 ppm), Ag, As, Cs e Se (<0,5 ppm), Ni (<20 ppm), $\mathrm{Cr}(0,002 \%), \mathrm{Mn}(0,01 \%)$, n.a. $=$ não analisados. QHG = quartzo-hornblenda gabro, GIA = Granito Igarapé Azul (Fácies Vila Catarina) e GC = Granito Caroebe (Fácies Jaburuzinho). Amostras GIA e GC de Almeida (2007).

\begin{tabular}{|c|c|c|c|c|c|c|c|c|c|c|c|c|c|c|c|c|c|}
\hline & $\mathrm{Ba}$ & Co & $\mathrm{Cu}$ & $\mathrm{Ga}$ & $\mathrm{Hf}$ & $\mathrm{Nb}$ & $\mathrm{Ni}$ & $\mathrm{Pb}$ & $\mathrm{Rb}$ & $\mathrm{Sc}$ & $\mathrm{Sr}$ & Th & U & V & $Y$ & $\mathrm{Zn}$ & $\mathrm{Zr}$ \\
\hline CM-01 & 49,0 & 16,3 & 246 & 39,6 & 7,4 & 11,2 & 58,0 & 18,6 & 2,3 & 42,0 & 22,3 & 18,0 & 4,0 & 989 & 12,0 & 39,0 & 326 \\
\hline CM-02 & 74,0 & 9,2 & 130 & 25,7 & 4,0 & 8,3 & 30,5 & 2,4 & 3,1 & 53,0 & 45,3 & 2,4 & 0,4 & 950 & 11,9 & 17,0 & 175 \\
\hline CM-03 & 64,0 & 28,6 & 176 & 38,6 & 5,5 & 7,3 & 51,5 & 23,6 & 0,8 & 45,0 & 42,8 & 8,4 & 2,4 & 1597 & 4,2 & 25,0 & 206 \\
\hline CM-04 & 4,0 & 109 & 124 & 40,0 & 1,6 & 2,6 & 134 & 2,5 & 0,2 & 23,0 & 1,1 & 0,9 & 0,6 & 2401 & 0,7 & 71,0 & 59,2 \\
\hline CM-05 & 40,0 & 25,2 & 66,5 & 64,0 & 1,3 & 5,5 & 152 & 0,6 & 0,4 & 17,0 & 11,2 & 0,2 & 0,1 & 2542 & 2,2 & 54,0 & 62,7 \\
\hline CM-06 & 43,0 & 52,2 & 72,7 & 19,7 & 1,7 & 5,5 & 120 & 5,1 & 2,7 & 12,0 & 19,0 & 0,7 & 0,2 & 627 & 16,8 & 134,0 & 94,6 \\
\hline CM-07 & 25,0 & 56,7 & 95,9 & 28,7 & 2,7 & 5,3 & 132 & 3,0 & 6,5 & 27,0 & 4,1 & 2,9 & 0,3 & 860 & 19,5 & 97,0 & 130 \\
\hline CM-08 & 53,0 & 48,4 & 365 & 34,0 & 3,4 & 4,9 & 382 & 48,4 & 2,4 & 23,0 & 3,6 & 1,9 & 8,6 & 1246 & 3,8 & 49,0 & 174 \\
\hline CM-09 & 38,0 & 45,2 & 306 & 37,0 & 2,4 & 1,5 & 92,5 & 7,1 & 3,1 & 17,0 & 5,1 & 2,2 & 1,4 & 1320 & 1,2 & 48,0 & 114 \\
\hline QHG & 263 & 48,5 & 89,1 & 21,2 & 4,6 & 14,5 & 44,7 & 2,3 & 10,1 & 25,0 & 530 & 3,0 & 0,7 & 338 & 21,4 & 40,0 & 215 \\
\hline CV-01 & 52,0 & 4,0 & 161 & 29,4 & 2,9 & 7,0 & 27,0 & 4,2 & 12,7 & 38,0 & 18,5 & 6,6 & 1,9 & 871 & 2,7 & 9,0 & 128 \\
\hline CV-02 & 25,0 & 4,8 & 50,3 & 28,1 & 4,2 & 4,5 & 59,0 & 21,5 & 4,6 & 76,0 & 3,8 & 31,2 & 4,9 & 572 & 2,5 & 13,0 & 177 \\
\hline CV-03 & 134 & 1,3 & 10,0 & 25,8 & 6,1 & 7,5 & $<20,0$ & 30,0 & 11,8 & 17,0 & 53,2 & 25,7 & 7,2 & 382 & 7,5 & 5,0 & 290 \\
\hline CV-04 & 39,0 & 0,7 & 8,4 & 24,3 & 4,5 & 10,5 & $<20,0$ & 32,3 & 9,6 & 18,0 & 16,7 & 30,5 & 5,0 & 521 & 2,4 & 3,0 & 197 \\
\hline CV-05 & 19,0 & 6,8 & 78,3 & 23,8 & 2,6 & 3,6 & 81,0 & 26,7 & 2,9 & 63,0 & 1,6 & 12,6 & 1,4 & 325 & 1,6 & 16,0 & 103 \\
\hline CV-06 & 88,0 & 1,8 & 19,5 & 44,2 & 5,4 & 11,6 & $<20,0$ & 24,5 & 9,1 & 32,0 & 21,2 & 39,1 & 5,9 & 459 & 2,9 & 9,0 & 221 \\
\hline CV-07 & 49,0 & 3,3 & 12,5 & 45,1 & 7,5 & 17,6 & $<20,0$ & 46,1 & 15,8 & 42,0 & 11,5 & 77,9 & 4,0 & 673 & 10,7 & 4,0 & 289 \\
\hline GIA & 1606 & n.a. & n.a. & 18,0 & 7,8 & 6,7 & 19,5 & n.a. & 127 & n.a. & 478 & 14,3 & 3,2 & 19,0 & n.a. & n.a. & 288 \\
\hline $\mathrm{GC}$ & 1639 & n.a. & n.a. & 23,1 & 9,7 & 11,1 & 16,2 & n.a. & 82,0 & n.a. & 1024 & 12,2 & 2,3 & 28,3 & n.a. & n.a. & 404 \\
\hline Média crosta maciça & 43,3 & 43,4 & 176 & 36,4 & 3,3 & 5,8 & 128 & 12,4 & 2,4 & 28,8 & 17,2 & 4,2 & 2,0 & 1392 & 8,0 & 59,3 & 149 \\
\hline Média crosta vermiforme & 58,0 & 3,2 & 48,6 & 31,5 & 4,7 & 8,9 & 55,7 & 26,5 & 9,5 & 40,9 & 18,1 & 31,9 & 4,3 & 543 & 4,3 & 8,4 & 201 \\
\hline
\end{tabular}



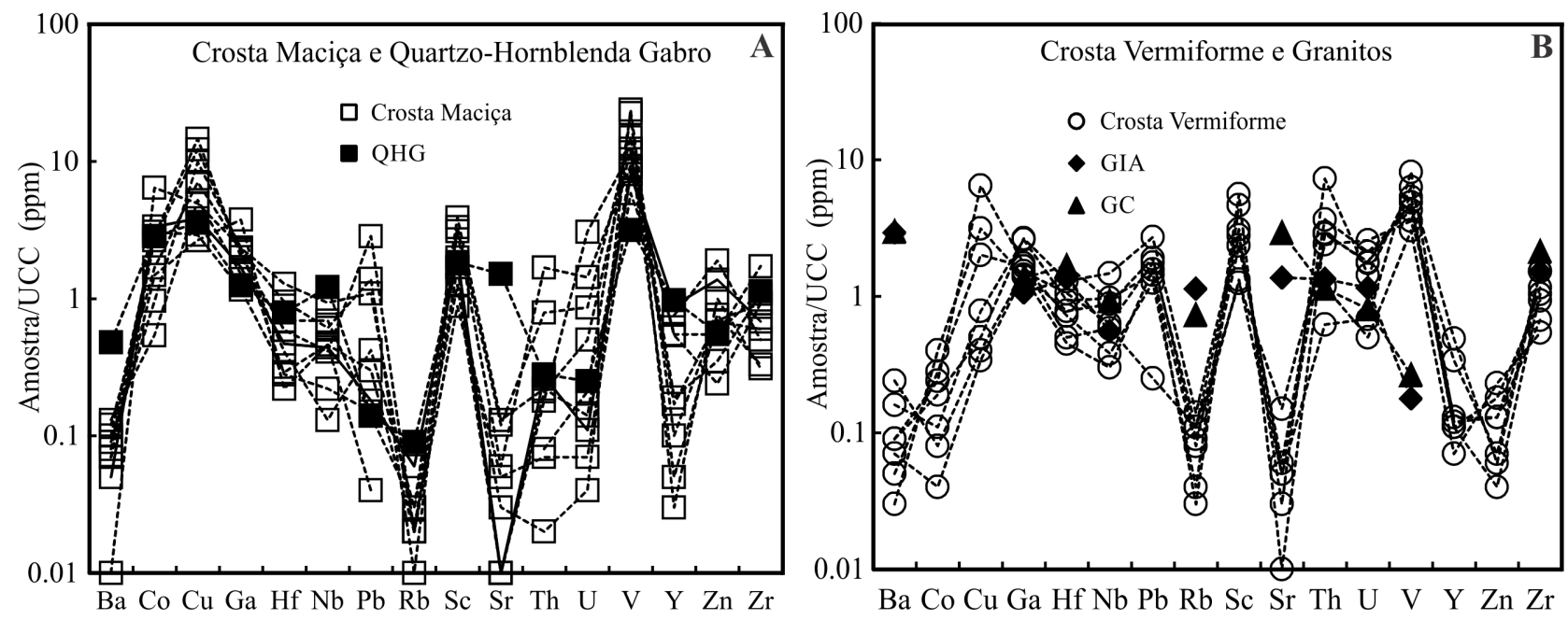

Figura 5. Diagramas de distribuição dos elementos traços em ppm, normalizados pela crosta continental superior de Taylor e McLennan (1985). A) Crosta maciça ferro-titanífera e QHG. B) Crosta vermiforme e granitos. QHG = quartzo-hornblenda gabro, GIA = Granito Igarapé Azul (Fácies Vila Catarina) e GC = Granito Caroebe (Fácies Jaburuzinho).

Tabela 3. Distribuição dos elementos terras raras em ppm das rochas, crostas maciças e vermiformes. QHG = quartzo-hornblenda gabro, GIA $=\mathrm{Granito}$ Igarapé Azul (Fácies Vila Catarina) e GC = Granito Caroebe (Fácies Jaburuzinho).

\begin{tabular}{|c|c|c|c|c|c|c|c|c|c|c|c|c|c|c|c|c|c|c|c|c|}
\hline & $\mathrm{La}$ & $\mathrm{Ce}$ & $\mathrm{Pr}$ & $\mathrm{Nd}$ & Sm & $\mathrm{Eu}$ & $\mathrm{Gd}$ & $\mathrm{Tb}$ & Dy & Ho & $\mathrm{Er}$ & $\mathrm{Tm}$ & $\mathrm{Yb}$ & $\mathrm{Lu}$ & $\Sigma$ ETRL & $\Sigma$ ETRP & $\Sigma$ ETR & $\mathrm{Ce} / \mathrm{Ce}$ * & $\begin{array}{l}\mathrm{Eu} / \\
\mathrm{Eu}^{*}\end{array}$ & $(\mathrm{La} / \mathrm{Yb}) \mathrm{N}$ \\
\hline CM-01 & 3,40 & 72,80 & 8,34 & 26,10 & 3,92 & 0,95 & 3,16 & 0,47 & 2,74 & 0,55 & 1,65 & 0,28 & 1,88 & 0,30 & 160,5 & 11,03 & 171,5 & 0,99 & 0,83 & 9,71 \\
\hline CM-02 & 29,20 & 61,80 & 7,82 & 31,20 & 6,31 & 1,56 & 5,20 & 0,66 & 3,85 & 0,67 & 1,63 & 0,25 & 1,95 & 0,23 & 137,9 & 14,44 & 152,3 & 0,99 & 0,84 & $<0,10$ \\
\hline CM-03 & 37,30 & 109,5 & 7,26 & 25,30 & 3,69 & 0,82 & 2,30 & 0,29 & 1,60 & 0,20 & 0,49 & 0,08 & 0,52 & 0,08 & 183,9 & 5,56 & 189,4 & 1,73 & 0,87 & $<0,10$ \\
\hline CM-04 & 1,20 & 3,20 & 0,21 & 0,90 & 0,09 & 0,07 & 0,20 & 0,03 & 0,30 & 0,05 & 0,06 & 0,02 & 0,10 & 0,02 & 5,67 & 0,78 & 6,45 & 1,44 & 1,41 & 1,10 \\
\hline CM-05 & 9,10 & 25,90 & 2,45 & 7,80 & 1,37 & 0,38 & 0,98 & 0,12 & 0,71 & 0,06 & 0,18 & 0,03 & 0,10 & 0,04 & 47,00 & 2,22 & 49,22 & 1,48 & 1,02 & 2,82 \\
\hline CM-06 & 10,30 & 22,30 & 2,37 & 8,30 & 1,55 & 0,64 & 2,27 & 0,34 & 3,01 & 0,71 & 1,87 & 0,27 & 1,27 & 0,27 & 45,46 & 10,01 & 55,47 & 1,18 & 1,05 & 8,53 \\
\hline CM-07 & 5,90 & 12,40 & 1,84 & 8,30 & 1,81 & 0,57 & 2,70 & 0,35 & 2,55 & 0,51 & 2,06 & 0,29 & 1,68 & 0,28 & 30,82 & 10,42 & 41,24 & 0,87 & 0,80 & 0,49 \\
\hline wCM-08 & 4,30 & 512,6 & 0,80 & 4,10 & 1,01 & 0,29 & 1,30 & 0,18 & 1,50 & 0,23 & 0,88 & 0,13 & 1,16 & 0,17 & 523,1 & 5,55 & 528,7 & 58,60 & 0,77 & 0,51 \\
\hline CM-09 & 8,00 & 27,00 & 1,04 & 3,60 & 0,43 & 0,10 & 0,26 & 0,05 & 0,27 & 0,08 & 0,18 & 0,04 & 0,15 & 0,05 & 40,17 & 1,08 & 41,25 & 2,42 & 0,92 & 7,14 \\
\hline QHG & 35,70 & 76,00 & 9,11 & 37,20 & 6,45 & 2,03 & 5,79 & 0,78 & 4,26 & 0,80 & 2,20 & 0,28 & 1,74 & 0,27 & 166,5 & 16,12 & 182,6 & 1,01 & 1,03 & 3,54 \\
\hline CV-01 & 13,10 & 21,80 & 2,42 & 8,60 & 1,28 & 0,33 & 1,06 & 0,14 & 0,65 & 0,13 & 0,35 & 0,05 & 0,32 & 0,05 & 47,53 & 2,75 & 50,28 & 0,99 & 0,87 & 5,47 \\
\hline CV-02 & 8,40 & 7,40 & 1,05 & 3,10 & 0,71 & 0,18 & 0,56 & 0,10 & 0,60 & 0,10 & 0,36 & 0,07 & 0,45 & 0,08 & 20,84 & 2,32 & 23,16 & 0,69 & 0,87 & 2,65 \\
\hline CV-03 & 36,00 & 71,30 & 7,78 & 28,00 & 3,78 & 0,87 & 2,95 & 0,36 & 1,83 & 0,30 & 0,82 & 0,11 & 0,74 & 0,12 & 147,7 & 7,23 & 155,0 & 1,09 & 0,81 & 6,62 \\
\hline CV-04 & 22,70 & 17,20 & 2,79 & 8,10 & 0,98 & 0,26 & 0,87 & 0,10 & 0,55 & 0,09 & 0,23 & 0,04 & 0,29 & 0,06 & 52,03 & 2,23 & 54,26 & 0,61 & 0,89 & 10,92 \\
\hline CV-05 & 2,50 & 6,40 & 0,52 & 1,80 & 0,36 & 0,11 & 0,37 & 0,06 & 0,37 & 0,09 & 0,26 & 0,05 & 0,39 & 0,06 & 11,69 & 1,65 & 13,34 & 1,43 & 0,95 & 0,89 \\
\hline CV-06 & 23,20 & 19,40 & 3,30 & 9,70 & 1,38 & 0,35 & 1,15 & 0,14 & 0,76 & 0,13 & 0,34 & 0,05 & 0,37 & 0,07 & 57,33 & 3,01 & 60,34 & 0,63 & 0,87 & 3,56 \\
\hline
\end{tabular}


Tabela 3. Continuação

\begin{tabular}{|c|c|c|c|c|c|c|c|c|c|c|c|c|c|c|c|c|c|c|c|c|}
\hline & $\mathrm{La}$ & $\mathrm{Ce}$ & $\mathrm{Pr}$ & $\mathrm{Nd}$ & Sm & Eu & $\mathrm{Gd}$ & $\mathrm{Tb}$ & Dy & Ho & $\mathrm{Er}$ & $\mathrm{Tm}$ & $\mathrm{Yb}$ & Lu & $\Sigma$ ETRL & $\Sigma$ ETRP & $\Sigma$ ETR & $\mathrm{Ce} / \mathrm{Ce}^{*}$ & $\begin{array}{l}\mathrm{Eu} / \\
\mathrm{Eu}^{*}\end{array}$ & $(\mathrm{La} / \mathrm{Yb}) \mathrm{N}$ \\
\hline CV-07 & 40,10 & 76,70 & 9,45 & 30,60 & 4,01 & 0,42 & 2,45 & 0,34 & 1,86 & 0,42 & 1,35 & 0,21 & 1,57 & 0,23 & 161,3 & 8,43 & 169,7 & 1,06 & 0,41 & 2,06 \\
\hline GIA & 139,6 & 228,2 & 27,19 & 93,99 & 12,22 & 2,05 & 6,94 & 0,83 & 3,41 & 0,54 & 1,49 & 0,23 & 1,85 & 0,28 & 503,2 & 15,57 & 518,8 & 0,97 & 0,69 & 10,37 \\
\hline $\mathrm{GC}$ & 43,02 & 73,26 & 8,61 & 30,45 & 4,60 & 0,72 & 3,19 & 0,45 & 2,36 & 0,45 & 1,40 & 0,22 & 1,67 & 0,26 & 160,7 & 9,99 & 170,6 & 0,98 & 0,58 & 3,53 \\
\hline $\begin{array}{l}\text { Média } \\
\text { crosta } \\
\text { maciça }\end{array}$ & 17,08 & 94,17 & 3,57 & 12,84 & 2,24 & 0,60 & 2,04 & 0,28 & 1,84 & 0,34 & 1,00 & 0,15 & 0,98 & 0,16 & 130,50 & 6,79 & 137,29 & 7,74 & 0,95 & 3,36 \\
\hline $\begin{array}{c}\text { Média } \\
\text { crosta } \\
\text { vermiforme }\end{array}$ & 20,86 & 31,46 & 3,90 & 12,84 & 1,79 & 0,36 & 1,34 & 0,18 & 0,95 & 0,18 & 0,53 & 0,08 & 0,59 & 0,10 & 71,20 & 3,95 & 75,15 & 0,93 & 0,81 & 4,60 \\
\hline
\end{tabular}

o maior fracionamento dos ETRL em relação aos ETRP na crosta vermiforme (em média 4,60) quando considerada a crosta continental superior de Taylor e McLennan (1985). Há anomalia leve positiva em Eu/Eu* no QHG e em três amostras das crostas maciças (CM-04, CM-05 e CM-06), assim como acentuada anomalia positiva de Ce em CM-03, CM-04, CM-05, CM-08 e CM-09 (Figura 6A).

\section{DISCUSSÃO}

A integração estatística entre a análise de fatores e a análise de agrupamento identificou três associaçóes geoquímicas: 1) PF-Cu$\mathrm{Co}-\mathrm{V}-\mathrm{TiO}_{2}-\mathrm{Fe}_{2} \mathrm{O}_{3}$; 2) $\left.\mathrm{Al}_{2} \mathrm{O}_{3}-\mathrm{P}_{2} \mathrm{O}_{5}-\mathrm{Nb}-\mathrm{Zr}-\mathrm{Hf} ; 3\right)$ ETR-Sr-Rb$\mathrm{Ba}-\mathrm{SiO}_{2}$ (Figura 7) e discriminou três grupos de amostras: 1 ) as rochas; 2) as crostas maciças CM-02, CM-03, CM-04, CM-05, CM-06, CM-07, CM-08 e CM-09 e a crosta vermiforme CV01; 3) as crostas vermiformes CV-02, CV-03, CV-04, CV-05, CV-06 e CV-07 e a crosta maciça CM-01.

No grupo das rochas o QHG tem baixa correlação com os granitos devido ao menor teor de $\mathrm{SiO}_{2}, \mathrm{Ba}, \mathrm{Rb}, \mathrm{Sr}$ e ETR. A crosta maciça é identificada pela associação PF-Cu-Co-V-TiO $\mathrm{Fe}_{2} \mathrm{O}_{3}$ em consequência da paragênese magnetita, maghemita, hematita, ilmenita, goethita e anatásio, onde a PF é controlada pela presença de goethita é mais abundante que a caulinita nas crostas maciças. A associação que define a crosta vermiforme é $\mathrm{Al}_{2} \mathrm{O}_{3}-\mathrm{P}_{2} \mathrm{O}_{5}-\mathrm{Nb}-\mathrm{Zr}-\mathrm{Hf}$ devido a maior quantidade de caulinita, assim como de resistatos em relação a maciça (Figura 7).

$\mathrm{O}$ cálculo isoquímico entre a rocha e a crosta demonstra o enriquecimento em $\mathrm{Fe}_{2} \mathrm{O}_{3}, \mathrm{PF}, \mathrm{e} \mathrm{V}(\mathrm{FE}=1,6$ a 12,5) na $\mathrm{s}$ crosta maciça, exceto a amostra CM-05 onde o $\mathrm{Fe}_{2} \mathrm{O}_{3}$ e PF são imóveis e onde há grande concentração de $\mathrm{TiO}_{2}$ e pouca quantidade de goethita. Sílica, $\mathrm{P}_{2} \mathrm{O}_{5}, \mathrm{Ba}, \mathrm{Co}, \mathrm{Rb}, \mathrm{Sr}$ e Y estão empobrecidos $(\mathrm{FE}=<0,1$ a 0,7$)$ em quase todas as amostras e o Co é imóvel nas amostras CM-04 e CM-06. Os demais elementos $\mathrm{Cu}, \mathrm{Ga}, \mathrm{Hf}, \mathrm{Nb}, \mathrm{Pb}, \mathrm{Sc}$, Th, U, Zn, Zr e ETR, estão ora enriquecidos ora empobrecidos e, portanto não são diagnósticos do processo laterítico, entretanto entre eles o $\mathrm{Pb}$ é único elemento que na maior parte das amostras está enriquecido. Cobre, Ga, Hf, Nb, Sc, Th, U, Zn, Zr e ETR são empobrecidos (Tabela 4), entretanto a grande maioria deles está enriquecida na amostra CM-01, onde o $\mathrm{Al}_{2} \mathrm{O}_{3}$ tem o teor mais elevado dentre as amostras da crosta maciça, por isso se agrupa com a crosta vermiforme (Figura 7). A amostra CM-08 apresenta enriquecimento de $\mathrm{Ce}(\mathrm{FE}=4,2)$ e condiciona a anomalia positiva nesse elemento, enquanto o enriquecimento de $\mathrm{Cu}, \mathrm{Pb}$ e U sugere que grande parte dos elementos traços está associado aos argilominerais.

O balanço geoquímico das crostas vermiformes em relação aos granitoides é similar ao da crosta maciça em relação ao QHG, mas o enriquecimento de Fe, V e PF (FE = 2,5 a 24,1) é mais acentuado, em consequência da maior quantidade de argilominerais (Tabela 4).

Normalmente a textura e a composição mineral e, consequentemente a composição química das crostas estáo relacionadas ao estágio da lateritização e, secundariamente a composição da rocha mãe. $\mathrm{Na}$ Amazônia perfis lateríticos mais antigos são identificadas por texturas mais complexas e pelo elevado conteúdo de gibbsita que em casos extremos pode formar um horizonte bauxítico. Esses perfis se desenvolveram no Oligoceno a partir de rochas do Cretáceo, como as Formaçóes Alter do Chão e Itapecuru (Boulangé e Carvalho 1997; Kotschoubey et al. 2005; e Costa et al. 2014) ou mais antigas, como as do Proterozóico (Peixoto e Horbe 2008; Soler e Lasaga 2000). As crostas mais jovens se formaram no Plio-Pleistoceno sobre as rochas das formaçóes Barreiras e Novo Remanso do Mioceno (Costa e Horbe 1997; Rozo et al. 2005, Costa et al. 2009).

Em Nova Colina, o contexto geológico e a lateritização favoreceram o desenvolvimento de crostas maciça e vermiforme. A crosta maciça diferencia-se da vermiforme pela posição topográfica mais elevada, pela textura, pela ocorrência 

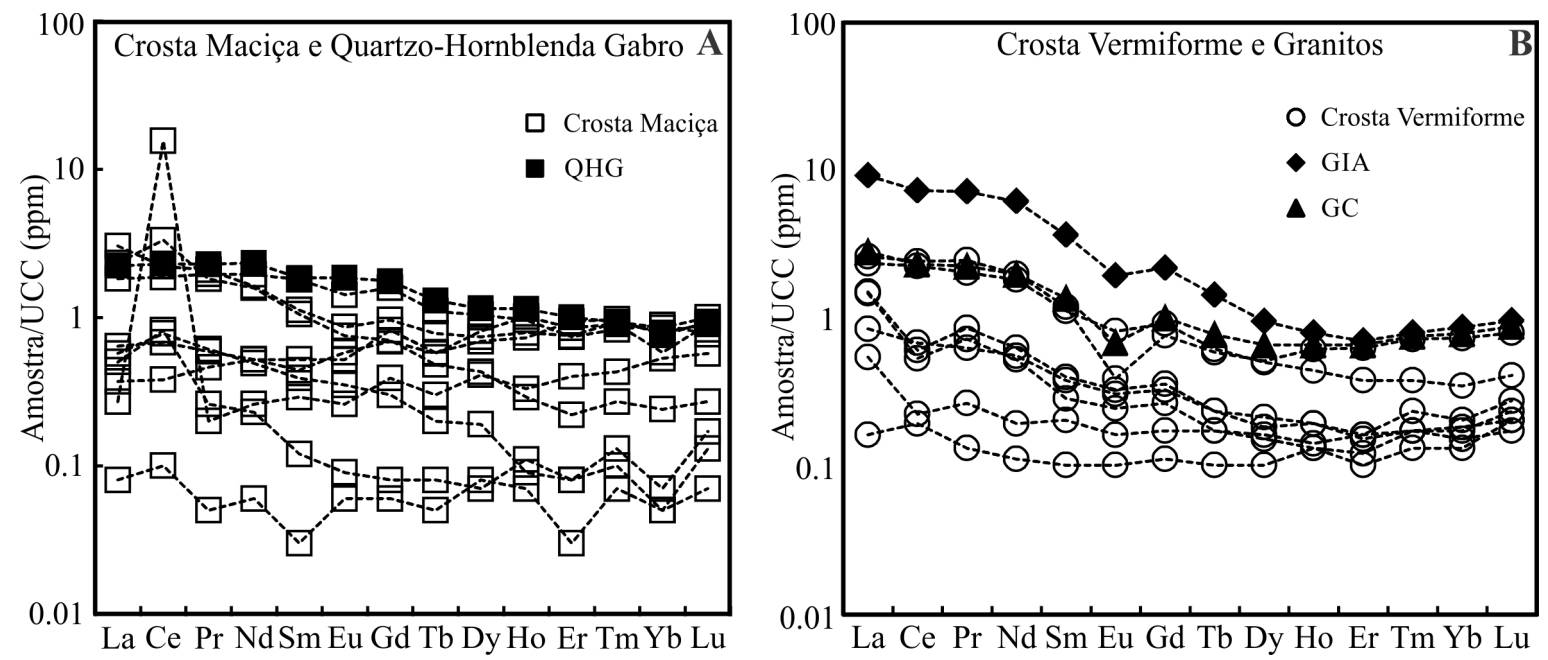

Figura 6. Diagramas dos elementos terras raras em ppm, normalizados pela crosta continental superior de Taylor e McLennan (1985). A) Crosta maciça ferro-titanífera QHG. B) Crosta vermiforme e granitos. QHG = quartzo-hornblenda gabro, GIA = Granito Igarapé Azul (Fácies Vila Catarina) e GC = Granito Caroebe (Fácies Jaburuzinho).
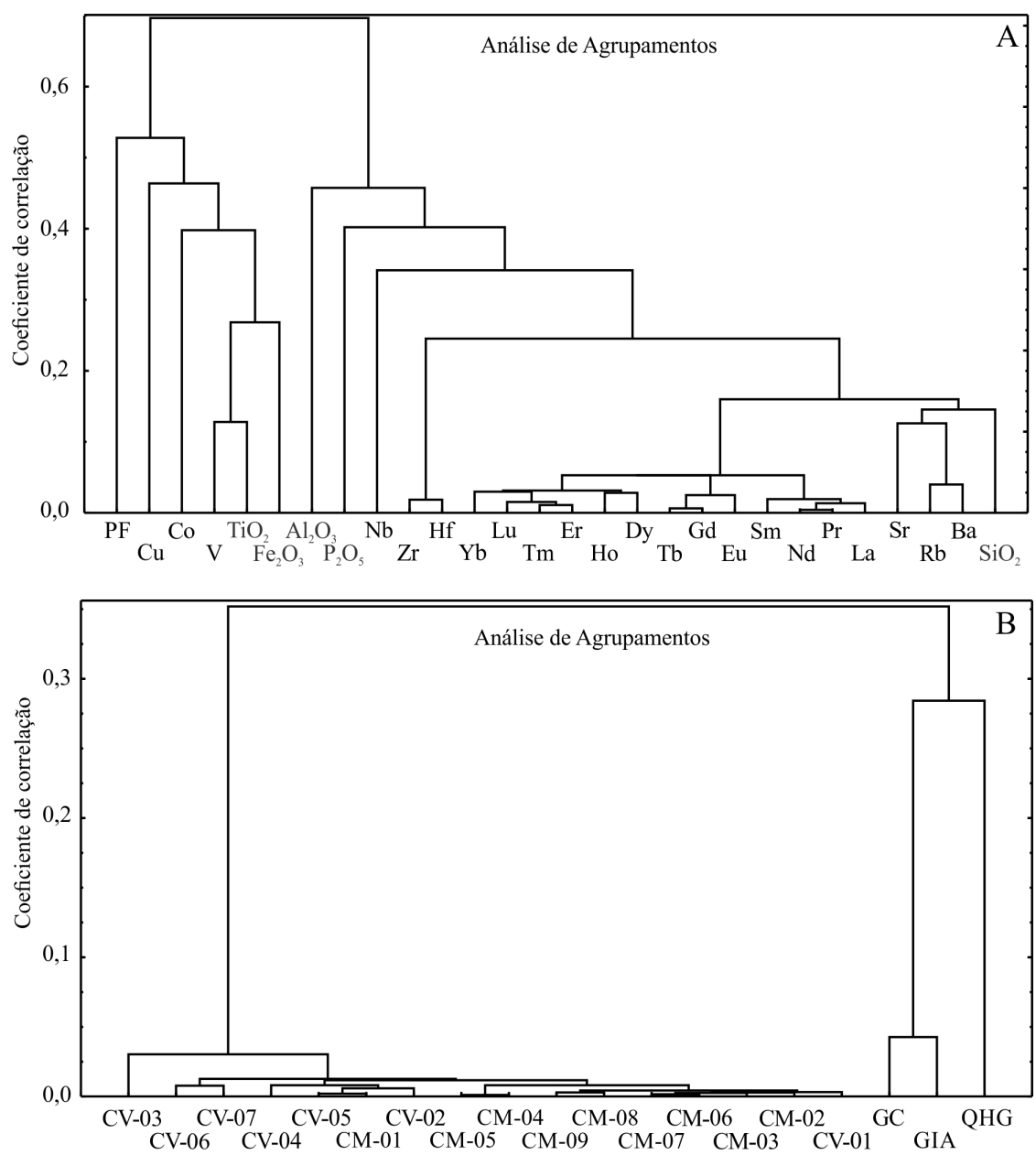

Figura 7. Análise de agrupamento em modo simples dos elementos químicos indicando: (A) as associações geoquímicas 1) $\mathrm{PF}-\mathrm{Cu}_{-} \mathrm{Co}_{-}-\mathrm{V}^{-} \mathrm{TiO}_{2}-\mathrm{Fe}_{2} \mathrm{O}_{3} ; 2$ ) $\mathrm{Al}_{2} \mathrm{O}_{3}$ $\left.\mathrm{P}_{2} \mathrm{O}_{5}-\mathrm{Nb}-\mathrm{Zr}-\mathrm{Hf} ; 3\right)$ ETR-Sr-Rb-Ba-SiO ${ }_{2} \mathrm{e}(\mathrm{B})$ as diferenças químicas entre as rochas e crostas de Nova Colina. 
Tabela 4. Resultado do cálculo do balanço isozircônio das crostas maciça e vermiforme. n.a. = não analisados. $\mathrm{FE}>1,1$ são considerados enriquecidos, $\mathrm{FE}$ entre 0,9 e 1,1 considerados imóveis e $\mathrm{FE}<0,9$ considerados empobrecidos em relação a rocha mãe.

\begin{tabular}{|c|c|c|c|c|c|c|c|c|c|c|c|c|c|c|c|c|}
\hline & CM-01 & CM-02 & CM-03 & CM-04 & CM-05 & CM-06 & CM-07 & CM-08 & CM-09 & CV-01 & CV-02 & CV-03 & CV-04 & CV-05 & CV-06 & CV-07 \\
\hline $\mathrm{SiO}_{2}$ & 0,5 & 0,2 & 0,2 & $<0,1$ & $<0,1$ & 0,2 & 0,2 & 0,1 & 0,1 & 0,2 & 0,4 & 0,7 & 0,4 & 0,3 & 0,3 & 0,4 \\
\hline $\mathrm{Fe}_{2} \mathrm{O}_{3}$ & 3,9 & 2,7 & 2,3 & 2,2 & 0,9 & 3,8 & 2,6 & 2,9 & 2,7 & 8,0 & 13,0 & 16,6 & 10,5 & 12,0 & 7,6 & 10,3 \\
\hline $\mathrm{P}_{2} \mathrm{O}_{5}$ & 0,8 & 0,1 & 0,2 & 0,1 & $<0,1$ & 0,2 & 0,1 & 0,3 & 0,1 & 0,3 & 0,2 & 0,4 & 0,2 & 0,2 & 0,2 & 0,2 \\
\hline PF & 12,5 & 2,9 & 4,8 & 2,6 & 0,9 & 5,2 & 4,0 & 2,9 & 4,6 & 8,9 & 14,8 & 16,8 & 9,2 & 12,0 & 11,6 & 7,8 \\
\hline $\mathrm{Ba}$ & 0,2 & 0,2 & 0,2 & $<0,1$ & $<0,1$ & 0,1 & 0,1 & 0,1 & 0,1 & $<0,1$ & $<0,1$ & 0,1 & $<0,1$ & $<0,1$ & $<0,1$ & $<0,1$ \\
\hline Co & 0,4 & 0,1 & 0,4 & 1,0 & 0,1 & 1,0 & 0,7 & 0,6 & 0,6 & n.a. & n.a. & n.a. & п.а. & n.a. & n.a. & n.a. \\
\hline $\mathrm{Cu}$ & 3,6 & 0,9 & 1,3 & 0,6 & 0,2 & 0,7 & 0,7 & 2,6 & 2,2 & n.a. & n.a. & n.a. & n.a. & n.a. & n.a. & n.a. \\
\hline Ga & 2,4 & 0,8 & 1,2 & 0,8 & 0,7 & 0,8 & 0,9 & 1,0 & 1,1 & 0,8 & 1,4 & 1,7 & 0,9 & 1,0 & 1,4 & 1,7 \\
\hline $\mathrm{Hf}$ & 2,1 & 0,5 & 0,8 & 0,2 & 0,1 & 0,3 & 0,4 & 0,5 & 0,3 & 0,2 & 0,5 & 1,0 & 0,4 & 0,3 & 0,4 & 0,7 \\
\hline $\mathrm{Nb}$ & 1,0 & 0,4 & 0,3 & 0,1 & 0,1 & 0,3 & 0,2 & 0,2 & 0,1 & 0,5 & 0,5 & 1,2 & 0,9 & 0,4 & 0,9 & 1,5 \\
\hline $\mathrm{Pb}$ & 10,4 & 0,7 & 6,6 & 0,5 & 0,1 & 2,0 & 0,8 & 13,2 & 2,0 & n.a. & n.a. & n.a. & п.а. & п.а. & n.a. & n.a. \\
\hline $\mathrm{Rb}$ & 0,3 & 0,2 & 0,1 & $<0,1$ & $<0,1$ & 0,2 & 0,4 & 0,2 & 0,2 & 0,1 & $<0,1$ & 0,2 & 0,1 & $<0,1$ & 0,1 & 0,1 \\
\hline $\mathrm{Sc}$ & 2,2 & 1,3 & 1,2 & 0,4 & 0,2 & 0,4 & 0,7 & 0,6 & 0,4 & п.а. & n.a. & n.a. & n.a. & n.a. & n.a. & n.a. \\
\hline $\mathrm{Sr}$ & 0,1 & 0,1 & 0,1 & $<0,1$ & $<0,1$ & $<0,1$ & $<0,1$ & $<0,1$ & $<0,1$ & $<0,1$ & $<0,1$ & 0,1 & $<0,1$ & $<0,1$ & $<0,1$ & $<0,1$ \\
\hline Th & 7,7 & 0,5 & 1,8 & 0,1 & $<0,1$ & 0,2 & 0,6 & 0,4 & 0,5 & 0,3 & 2,4 & 2,7 & 1,8 & 0,8 & 2,0 & 4,4 \\
\hline U & 7,4 & 0,4 & 2,2 & 0,4 & $<0,1$ & 0,3 & 0,3 & 7,7 & 1,3 & 0,4 & 1,8 & 3,7 & 1,5 & 0,4 & 1,4 & 1,1 \\
\hline V & 3,8 & 1,8 & 3,0 & 3,1 & 1,7 & 1,6 & 1,6 & 2,3 & 2,5 & 21,6 & 24,1 & 22,4 & 17,5 & 11,8 & 12,9 & 21,5 \\
\hline$Y$ & 0,7 & 0,4 & 0,1 & $<0,1$ & $<0,1$ & 0,7 & 0,6 & 0,1 & $<0,1$ & n.a. & n.a. & n.a. & n.a. & n.a. & n.a. & n.a. \\
\hline $\mathrm{Zn}$ & 1,3 & 0,3 & 0,4 & 0,8 & 0,3 & 3,0 & 1,5 & 0,8 & 0,8 & n.a. & n.a. & n.a. & n.a. & n.a. & n.a. & n.a. \\
\hline $\mathrm{Zr}$ & 2,0 & 0,5 & 0,6 & 0,1 & 0,1 & 0,4 & 0,4 & 0,5 & 0,3 & 0,2 & 0,5 & 1,2 & 0,5 & 0,3 & 0,4 & 0,6 \\
\hline La & 1,8 & 0,5 & 0,7 & $<0,1$ & 0,1 & 0,3 & 0,1 & 0,1 & 0,1 & 0,1 & 0,1 & 0,6 & 0,2 & $<0,1$ & 0,2 & 0,3 \\
\hline Ce & 1,2 & 0,5 & 0,9 & $<0,1$ & 0,1 & 0,3 & 0,1 & 4,2 & 0,2 & 0,1 & 0,1 & 0,7 & 0,1 & $<0,1$ & 0,1 & 0,4 \\
\hline $\mathrm{Pr}$ & 1,2 & 0,5 & 0,5 & $<0,1$ & 0,1 & 0,2 & 0,1 & 0,1 & 0,1 & 0,1 & 0,1 & 0,6 & 0,1 & $<0,1$ & 0,1 & 0,4 \\
\hline $\mathrm{Nd}$ & 0,9 & 0,5 & 0,4 & $<0,1$ & 0,1 & 0,2 & 0,1 & 0,1 & 0,1 & 0,1 & 0,1 & 0,6 & 0,1 & $<0,1$ & 0,1 & 0,4 \\
\hline $\mathrm{Sm}$ & 0,8 & 0,6 & 0,4 & $<0,1$ & 0,1 & 0,2 & 0,2 & 0,1 & $<0,1$ & 0,1 & 0,1 & 0,6 & 0,1 & $<0,1$ & 0,1 & 0,4 \\
\hline Eu & 0,6 & 0,5 & 0,3 & $<0,1$ & $<0,1$ & 0,3 & 0,2 & 0,1 & $<0,1$ & 0,1 & 0,1 & 0,9 & 0,2 & 0,1 & 0,2 & 0,2 \\
\hline $\mathrm{Gd}$ & 0,7 & 0,6 & 0,3 & $<0,1$ & $<0,1$ & 0,4 & 0,3 & 0,1 & $<0,1$ & 0,1 & 0,1 & 0,8 & 0,1 & 0,1 & 0,2 & 0,4 \\
\hline $\mathrm{Tb}$ & 0,8 & 0,5 & 0,2 & $<0,1$ & $<0,1$ & 0,4 & 0,3 & 0,1 & $<0,1$ & 0,1 & 0,2 & 0,8 & 0,1 & 0,1 & 0,2 & 0,4 \\
\hline Dy & 0,8 & 0,6 & 0,2 & $<0,1$ & $<0,1$ & 0,6 & 0,4 & 0,2 & $<0,1$ & 0,1 & 0,2 & 0,9 & 0,2 & 0,1 & 0,2 & 0,5 \\
\hline Ho & 0,9 & 0,5 & 0,2 & $<0,1$ & $<0,1$ & 0,8 & 0,4 & 0,2 & 0,1 & 0,2 & 0,2 & 0,8 & 0,1 & 0,2 & 0,2 & 0,6 \\
\hline $\mathrm{Er}$ & 1,0 & 0,5 & 0,1 & $<0,1$ & $<0,1$ & 0,8 & 0,6 & 0,3 & 0,1 & 0,1 & 0,3 & 0,8 & 0,1 & 0,2 & 0,2 & 0,7 \\
\hline $\mathrm{Tm}$ & 1,3 & 0,6 & 0,2 & $<0,1$ & $<0,1$ & 0,9 & 0,7 & 0,3 & 0,1 & 0,1 & 0,3 & 0,7 & 0,1 & 0,2 & 0,1 & 0,7 \\
\hline $\mathrm{Yb}$ & 1,4 & 0,7 & 0,2 & $<0,1$ & $<0,1$ & 0,6 & 0,6 & 0,4 & 0,1 & 0,1 & 0,3 & 0,6 & 0,1 & 0,2 & 0,1 & 0,7 \\
\hline Lu & 1,4 & 0,5 & 0,2 & $<0,1$ & $<0,1$ & 0,9 & 0,7 & 0,4 & 0,1 & 0,1 & 0,3 & 0,6 & 0,2 & 0,2 & 0,2 & 0,7 \\
\hline
\end{tabular}


de titanomagnetita e ilmenita e pela maior concentração de magnetita e gibbsita, além dos elevados teores de $\mathrm{TiO}_{2}, \mathrm{~V}$, $\mathrm{Cu}$ e Zr. Essas características indicam que a crosta maciça náo pode ser considerada como marcadora de um perfil maturo (com crosta bauxítica) e, portanto formado no Oligoceno, mas a ausência de gibbsita na crosta vermiforme é um critério que a correlaciona com perfis formados no Plio-Pleistoceno. Outro critério que indica que a lateritizaçáo que formou a crosta maciça foi de intensidade moderada é a elevada proporção de ilmenita e titanomagnetita em relação a anatásio comparativamente às crostas de Maicuru e Maraconaí consideradas como maturas (Oliveira et al. 1988; Angélica e Costa 1991 e 1993). Contudo, o teor de $\mathrm{TiO}_{2}$ no QHG $(2,24 \%)$ é inferior ao de Maicuru (aproximadamente 10\%) e Maraconaí (até 6\%), o que pode também explicar a baixa quantidade de anatásio na crosta maciça em Nova Colina.

Com base nos resultados apresentados, é possível inferir que a lateritizaçáo na regiāo de Nova Colina ocorreu em pelo menos duas fases distintas: a mais antiga gerou a crosta ferro-titanífera maciça com gibbsita e a mais recente a crosta vermiforme essencialmente caulinítica. O Cráton das Guianas onde se insere geologicamente a regiáo, está exposto à lateritização e a erosão há pelo menos $100 \mathrm{Ma}$ (Tardy e Roquin 1998). Nessa condição crostas lateríticas se formaram desde entấo, assim como foram afetadas por erosão. A fase erosiva mais recente e que configurou o relevo atual da regiáo, está provavelmente relacionada a subsidência no Mioceno da bacia do Tacutu (Milani e Thomaz Filho 2000), localizada a norte da regiáo de Nova Colina. Portanto, a crosta maciça de Nova Colina, assim como a crosta da Serra da Prata mais a norte (Santos 2011), são relictos dessa fase erosiva que afetou a regiâo centro sul de Roraima e truncou as crostas formadas no Oligoceno (época de formação das crostas lateríticas mais antigas - Kotschoubey et al. 2005). A ausência de gibbsita na crosta vermiforme e sua associaçáo lateral com blocos de granitos sugerem que o truncamento pela erosão foi mais profundo nessas rochas o que resultou no relevo baixo e aplainado. A crosta maciça que se insere topograficamente na superfície mais elevada dos Planaltos Residuais de Roraima (Franco et al. 1975), foi mais resistente a erosão configurando um alto topográfico. Nessa condição houve preservaçáo da parte inferior do perfil, provavelmente o saprólito e o horizonte mosqueado o que facilitou a formação da crosta laterítica pós erosão e a transformação de caulinita em gibbsita, enquanto na área dos granitos a erosáo truncou mais profundamente os perfis com exposição de rocha.

\section{CONCLUSÕES}

Os dois tipos de crostas lateríticas existentes na região de Nova Colina mostram que processos lateríticos e erosivos atuaram na regiâo. Esses processos são marcados pela composição mineral e geoquímica das crostas maciça e vermiforme que retratam substratos distintos. A crosta maciça ferro-titanífera com posição topográfica um pouco mais elevada $(220 \mathrm{~m})$ (Planaltos Residuais de Roraima), se desenvolveu a partir do QHG, provavelmente após o Mioceno a partir do saprólito e mosqueado exposto. A crosta vermiforme representativa do Pediplano Rio Branco-Rio Negro, desenvolvida a partir dos granitos (Caroebe e Igarapé Azul) e topograficamente mais rebaixada $(140 \mathrm{~m})$ é mais jovem e representa a lateritização imatura relacionada ao PlioPleistoceno. O teor de $\mathrm{TiO}_{2}$ de até $10 \%$ na crosta maciça, é em média seis vezes mais elevado que na crosta vermiforme e 16 vezes mais elevado que a crosta continental superior, mas é inferior ao das crostas de Maicuru e Maraconaí. Isto indica que o potencial mineral para $\mathrm{TiO}_{2}$ é pequeno já que a extensão da crosta maciça é de aproximadamente $1 \mathrm{~km}$.

\section{AGRADECIMENTOS}

Os autores agradecem ao Conselho Nacional de Desenvolvimento Científico e Tecnológico (CNPq, processo no. 473359/2012-0) e a Coordenação de Aperfeiçoamento de Pessoal de Nível Superior (CAPES) pelo apoio financeiro. A Universidade Federal do Amazonas e Universidade de Brasília pela sua infraestrutura. Aos professores Dr. Valmir da Silva Souza e Dr. Nilson Francisquini Botelho e a Frederico Alberto Cuadros Jimenéz pelo apoio nas análises de microscopia e microssonda realizadas na Universidade de Brasília. Agradecemos também ao Sr. Áureo detentor dos alvarás de pesquisa e que nos levou até a área.

\section{BIBLIOGRAFIA CITADA}

Almeida, M.E. 2006. Evolução geológica da porção centro-sul do Escudo das Guianas com base no estudo geoquímico, geocronológico e isotópico dos granitóides Paleoproterozóicos do Sudeste de Roraima, Brasil. Tese de Doutorado, Universidade Federal do Pará, Belém, Pará. 240p.

Almeida, M.E.; Macambira, M.J.B.; Oliveira, E.C. 2007. Geochemistry and zircon geochronology of the I-type high-K calc-alkaline and S-type granitoid rocks from southeastern Roraima, Brazil: Orosirian collisional magmatism evidence $(1.971 .96 \mathrm{Ga})$ in central portion of Guyana Shield. Precambrian Research, 155: 69-97.

Almeida, M.E.; Macambira, M.J.B. 2007. Geology and petrography of Paleoproterozoic granitoids from Uatumä-Anauá Domain, central region of Guyana Shield, southeastern Roraima, Brazil. Revista Brasileira de Geociências, 32:237-256.

Anand, R.R.; Paine, M. 2002. Regolith geology of the Yilgard Craton, Western Australia: implication for exploration. Australian Journal of Earth Science, 49: 3-162.

Angélica, R.S.; Costa, M.L. 1991. Associações geoquímicas nos lateritos superficiais do Complexo de Maicuru, Estado do Pará. Geochimica Brasiliensis, 5: 101-115. 
Angélica, R.S.; Costa, M.L. 1993. Geochemistry Of Rare-Earth Elements In Surface Lateritic Rocks And Soils From The Maicuru Complex, Para, Brazil. Journal of Geochemical Exploration, 47: 165-182.

Beauvais, A.; Roquin, C. 1996. Petrological differentiation patterns and geomorphic distribution of ferricretes in Central Africa. Geoderma, 73: 63-82.

Boulangé, B.; Carvalho, A. 1997. The bauxite of Porto Trombetas. In: Carvalho, A.; Boulangé, B.; Melfi, A. J.; Lucas, Y. (Eds.) Brazilian bauxites, USP/FAPESP/ORSTOM, Brazil. 55-73.

Carvalho, I.G.; Mestrinho, S.S.P.; Fontes, V.M.S.; Goel, O.P.; Souza, F.A. 1991. Geochemical evolution of laterites from two areas of the semiarid region in Bahia State, Brazil. Journal of Geochemical Exploration, 40: 385-411.

Conceição, D.A. 2011. Intemperismo na região da Serra do Tucano-RR. Dissertaçáo de Mestrado, Universidade Federal do Amazonas, Manaus, Amazonas. 41p.

Costa, M.L. 1991. Aspectos geológicos dos lateritos da Amazônia. Revista Brasileira de Geociências, 21: 146-160.

Costa, M.L.; Fonseca, L.R.; Angélica, R.S.; Lemos, V.P. 1991. Geochemical exploration of the Maicuru ultramafic-alkalinecarbonatite complex, northern Brazil. Journal of Geochemical Exploration, 40: 193-204.

Costa, M.L.; Fernandez, O.J.C.; Requelme, M.E.R. 2005. O depósito de manganês do Azul, Carajás: estratigrafia, mineralogia, geoquímica e evolução geológica. In: Marini, O.; Queiroz, E.T.; Ramos, B. W. (Editores). Caracterização em depósitos minerais em distritos mineiros da Amazônia. Brasília, ADIMB, 227-333.

Costa, M.L.; Horbe, A.M.C. 1997. Lateritização imatura sobreposta a lateritos maturos em Mãe do Rio, Estado do Para. In: Marcondes L Costa; Rômulo S Angélica. Contribuiçôes a Geologia da Amazonia 1: 339-357.

Costa, M.L. 1997. Lateritization as major process of ore deposit formation in the Amazon Region. Exploration Mining Geology, 6: 79-104.

Costa, M.L., 2007. Introdução ao intemperismo laterítico e à lateritização. In: Licht, O.A. B.; Mello, C.S.B.; Silva, C.R. (editores). Prospecção geoquímica de depósitos minerais metálicos, não metálicos, óleo e gás. São Paulo, SBGq, 788 p.

Costa, M.L.; Souza, D.J.L.; Angélica, R.S. 2009. The contribution of lateritization processes to the formation of the kaolin deposits from eastern Amazon. Journal of South American Earth Sciences, 27: 219-234

Costa, M.L.; Cruz, G.S.; Almeida, H.D.F.; Pollmann, H. 2014. On the geology, mineralogy and geochemistry of the bauxitebearing regolith in the lower Amazon basin: Evidence of genetic relationships. Journal of Geochemical Exploration, 146: 58-74.

Cox, K.G.; Bell, J.D.; Pankhurst, R.T. 1979. The Interpretation of Igneous Rocks. University Chicago Press, 450p.

Franco E.M.S.; Del `Arco J.O.; Rivetti, M. 1975. Folha NA.20 Boa Vista e parte das Folhas NA.21 Tumucumaque, NB.20 Roraima e Nb.21. In: Brasil. Projeto RADAMBRASIL. Geomorfologia. Rio de Janeiro. DNPM. P. 139-180. (Levantamentos de Recursos Naturais, 8).
Klein, C.; Dutrow, B. 2007. Manual of Science Mineral. 23rd ed. Hardcover, New York. 716p.

Kotschoubey, B.; Truckenbrodt, W.; Calaf, J.M.C. 2005. Evolução geológica da porção meridional da província bauxitífera de Paragominas durante o Neógeno/Pleistoceno (nordeste da Bacia do Grajaú, nordeste do Pará e extremo oeste de Maranhão. Revista Brasileira de Geociências, 35: 263-272.

Milani, E.J.; Thomaz Filho, A. 2000. Sedimentary Basins of South America. In: Cordani U.G.; Milani E.J.; Thomaz Filho A.; Campos D.A. Tectonic evolution of South America, Edição Especial do 31st International Geological Congress, 389-449.

Oliveira, C.M.; Fonseca, L.R.; Oliveira, N.P. 1988. A laterita titanífera de Maraconaí (PA). Anais do XXXV Congresso Brasileiro de Geologia: Belém, Pará. 1: 271-285.

Oliveira, F.S.; Varajão, A.F.D.C.; Varajāo, C.A.C.; Boulangé, B.; Soares, C.C.V. 2013. Mineralogical, micromorphological and geochemical evolution of the facies from the bauxite deposit of Barro Alto, Central Brazil. Catena, 105: 29-39.

Peixoto, S.F.; Horbe, A.M.C. 2008. Bauxitas do nordeste do Amazonas. Revista Brasileira de Geociências, 38: 406-422.

Rozo, J.M.G.; Nogueira, A.C.R.; Horbe, A.M.C.; Carvalho, A.S. 2005. Depósitos terciários da bacia do Amazonas. In: Adriana Maria Coimbra Horbe e Valmir da Silva Souza. (Org.). Contribuiçôes a Geologia da Amazônia 4: 201-207.

Santos, F.V. 2011. Intemperismo e as crostas lateriticas da região central de Roraima $-R R$. Dissertação de Mestrado, Universidade Federal do Amazonas, Manaus, Amazonas 43p.

Santos, J.O.S.; Hartman, L.A.; Gaudette, H.E.; Groves, D.I.; McNaughton, N.J.; Fletcher, I.R. 2000. A new understanding of the Provinces of the Amazon Craton based on integration of field mapping and U-Pb and Sm-Nd geochronology. Gondwana Research, 3: 453-488.

Schroeder, P.A.; Golvan, J.J.L., Roden, M.F. 2005. Weathering from granite and chlorite schist in the Georgia Piedmont. American Mineralogist, 87: 1616-1625.

Silva, M.L.M.C.; Oliveira, S.M.B. 1992. Caracterização mineralógica e química das bauxitas de Nazaré Paulista (São Paulo). Revista Brasileira de Geociências, 22: 93-99.

Silva, P.J.M.; Horbe, A.M.C.; Horbe, M.A. 2012. Mineralogia e geoquímica de ocorrências manganesíferas da bacia Alto Tapajós, sudeste do Amazonas, Brasil. Boletim do Museu Paraense Emílio Goeldi. Ciências Naturais, 7: 11-28.

Soler, J.M.; Lasaga, A.C. 2000. The Los Pijiguaos bauxite deposits (Venezuela): A compilation of field data and implications for the bauxitization process. Journal of South America Earth Science, 13: 47-65.

Streckeisen, A. L., 1976. Classification of the common igneous rocks by means of their chemical composition: a provisional attempt. Neues Jahrbuch for Mineralogie, Monatshefte, 1: 1-15.

Tardy, Y. 1993. Pétrologie des latérites et des sols tropicaux. Paris, Masson. 459p.

Tardy, Y.; Roquin, C. 1998. Dérive des continents, paleoclimat et altérations tropicales. BRGM. $473 \mathrm{p}$. 
Tassinari, C.C.G.; Macambira, M.J.B. 1999. Geochronological Provinces of the Amazonian Craton. Episodes, 22: 174-182.

Taylor, S.R.; McLennan, S.M. 1985. The continental Crust: its composition and evolution. An Examination of The Geochemical Record Preserved in Sedimentary Rocks. Blackwell Scientific Publ. $312 \mathrm{p}$.

Théveniaute, H.; Freyssinet, P. 1999. Paleomagnetism applied to lateritic profiles to assess saprolite and duricrust formation processes: the example of the Mont Baduel profile (French Guiana). Palaeogeography. Palaeoclimatology, Palaeoecology, 148: 209-231.

Tiesen, H.; Monaco, S.L.; Ramirez, A.; Santos, M.C.D.; Shang, C. 1996. Phospate minerals in a lateritic crust from Venezuela. Biogeochemistry, 34: 1-17.

Toledo, M.C.M.; Oliveira, S.M.B.; Costa, M.L.; Passos, C.M.; Almeida, H.D.F. 2006. Evoluçáo do manto de intemperismo laterítico rico em fosfatos na ilha de Itacupim (PA) - mineralogia, micromorfologia e geoquímica. Pesquisas em Geociências, 33: 109-122.

Recebido em 18/03/2015

Aceito em 22/06/2015 